UNIVERSIDADE DE SÃO PAULO

ESCOLA DE ENFERMAGEM

GABRIELA FAVARO FARIA GUERRER

\title{
AUDITORIA DE CONTAS EM UM HOSPITAL DE ENSINO ESPECIALIZADO EM CARDIOLOGIA E PNEUMOLOGIA: UM ESTUDO DE CASO
}

SÃO PAULO

2012 
GABRIELA FAVARO FARIA GUERRER

\section{AUDITORIA DE CONTAS EM UM HOSPITAL DE ENSINO ESPECIALIZADO EM CARDIOLOGIA E PNEUMOLOGIA: UM ESTUDO DE CASO}

Dissertação apresentada ao programa de Pós-Graduação em Gerenciamento de enfermagem da Escola de Enfermagem da Universidade de São Paulo para obtenção do título de Mestre em Ciências.

Área de Concentração:

Fundamentos e Práticas de Gerenciamento em Enfermagem

Orientador:

Prof. Dr. Antônio Fernandes Costa Lima

SÃO PAULO

2012 
AUTORIZO A REPRODUÇÃO E DIVULGAÇÃO TOTAL OU PARCIAL DESTE TRABALHO, POR QUALQUER MEIO CONVENCIONAL OU ELETRÔNICO, PARA FINS DE ESTUDO E PESQUISA, DESDE QUE CITADA A FONTE.

Assinatura:

Data:

Catalogação na Publicação (CIP)

Biblioteca "Wanda de Aguiar Horta"

Escola de Enfermagem da Universidade de São Paulo

\section{Guerrer, Gabriela Favaro Faria}

Auditoria de contas em um hospital de ensino especializado em cardiologia e pneumologia: um estudo de caso / Gabriela Favaro Faria Guerrer. -- São Paulo, 2012.

$82 \mathrm{p}$.

Dissertação (Mestrado) - Escola de Enfermagem da Universidade de São Paulo.

Orientador: Prof. Dr. Antônio Fernandes Costa Lima

Área de concentração: Gerenciamento em Enfermagem

1.Cardiologia 2. Auditoria 3. Documentação 4. Faturamento I. Título. 
Nome: Gabriela Favaro Faria Guerrer

Título: Auditoria de Contas em um Hospital de Ensino Especializado em Cardiologia e Pneumologia: um estudo de caso.

Dissertação apresentada ao Programa de Pós-Graduação em Gerenciamento de Enfermagem da Escola de Enfermagem da Universidade de São Paulo para obtenção do título de Mestre em Ciências

Aprovado em:

Banca Examinadora

Prof. Dr. Instituição:

Julgamento: Assinatura:

Prof. Dr. Instituição:

Julgamento: Assinatura:

Prof. Dr. Instituição: Julgamento: Assinatura: 
Aos meus pais Marina e Faria, pelo amor incondicional;

Ao meu irmão Rodrigo, pelo apoio e alegria;

Ao meu marido Tom, pelo amor e companheirismo em todos os momentos, principalmente naqueles em que mais precisei. 


\section{AGRADECIMENTOS}

Durante a realização deste trabalho recebi força e incentivo de pessoas especiais com as quais Deus me deu o privilégio de conviver:

Ao Professor Dr. Antônio Fernandes Costa Lima muito obrigada pelos ensinamentos, pela paciência, disponibilidade e competência na condução deste estudo.

Às Professoras Dras Valéria Castilho e Marli de Carvalho Jericó, obrigada pela contribuição e orientação no Exame de Qualificação.

Aos componentes do Grupo de Pesquisa Dimensão Econômica do Gerenciamento em Enfermagem, pela oportunidade de conhecer novas realidades e pelas valiosas contribuições para minha prática profissional.

Às minhas amigas e companheiras de jornada Renée Valeria Felipe Alves de Senna, Giuliana Tommaziello, Andréa Cunha Santos pelo imenso carinho e contribuição para a realização deste estudo.

Ao Dr. Antônio Tancredi, Irani Souza de Oliveira Scipioni, Edna Faria Assini, pelos bons conselhos e incentivo.

À Valéria Mattos, Vilma Souza, Célio Lahoz Barbeiro pela disponibilidade.

Ao Dr. Alfredo Manoel da Silva Fernandes pelo incentivo, amizade e paciência durante a condução deste estudo.

À Jane Maria Ribeiro do Prado pela disponibilidade na formatação da Dissertação.

À Nilma Maria Nunes Varjão Fonseca pela revisão das Referências.

A todos aqueles que contribuíram, direta ou indiretamente, para minha formação profissional, permitindo que eu compartilhe os ensinamentos adquiridos e crescimento pessoal... 


\section{RESUMO}

Guerrer GFF. Auditoria de Contas em um Hospital de Ensino Especializado em Cardiologia e Pneumologia: um estudo de caso [dissertação]. São Paulo: Escola de Enfermagem, Universidade de São Paulo; 2012.

As instituições hospitalares que prestam serviços às operadoras de planos de saúde investem na auditoria de contas visando à adequada remuneração do atendimento prestado. No momento da pré-análise das contas a equipe de auditoria realiza correções para fundamentar a cobrança dos procedimentos, evitar glosas e perdas de faturamento. Nesta perspectiva esta pesquisa objetivou verificar os itens componentes das contas dos pacientes internados, conferidos por enfermeiras, que mais receberam ajustes no momento da pré-análise; identificar o impacto dos ajustes no faturamento das contas analisadas pela equipe de auditoria (médicos e enfermeiras) do hospital após a pré-analise; calcular o faturamento que esta equipe consegue ajustar nas contas e identificar as glosas relacionadas aos itens por ela conferidos. Tratou-se de uma pesquisa exploratória, descritiva, retrospectiva, de abordagem quantitativa na modalidade de estudo de caso, desenvolvida no Instituto do Coração (InCor) do Hospital das Clínicas da Faculdade de Medicina da Universidade de São Paulo. Foram estudadas 2.613 contas pré-analisadas pela equipe de auditoria do InCor no período de janeiro a dezembro de 2011. O faturamento concentrou-se em $04(62,9 \%)$ das 34 operadoras de planos de saúde credenciadas. Houve predominância da operadora $A(27,6 \%)$, porém o maior valor médio obtido por conta referiu-se a operadora $D$ com $R \$ 19.187,50$. Os itens mais incluídos nas contas pelas enfermeiras foram gases $(90,5 \%)$; materiais de internação $(85 \%)$ e serviço de enfermagem $(83,2 \%)$. Materiais de Hemodinâmica com média de $R \$ 1.055,90$ (DP $\pm 3.953,45$ ); gases com média de $R \$ 707,91$ (DP \pm $843,95)$ e equipamentos com média de $\mathrm{R} \$ 689,42(\mathrm{DP} \pm 1145,20)$ constituíram os itens de maior impacto financeiro nesses ajustes. Os itens mais excluídos das contas referiram-se a medicamentos de internação (41,2\%); equipamentos (28\%) e serviços de enfermagem (17\%). Em relação aos ajustes negativos os itens que tiveram maior impacto financeiro foram os materiais de Hemodinâmica com média de $R \$ 3.860,15$ (DP $\pm 15.220,80$ ); medicamentos utilizados na Hemodinâmica com média de $R \$ 1.983,04(\mathrm{DP} \pm 8.324,42)$ e gases com média de $\mathrm{R} \$ 1.048,51$ (DP \pm 3.025,53). As enfermeiras incluíram $R \$ 1.877 .168,64$ e excluíram $R \$ 1.155 .351,36$ e os médicos incluíram $R \$ 563.927,46$ e excluíram $R \$ 657.190,19$. Caso não fosse realizada a pré-análise, haveria a perda de $R \$ 628.554,55$ no faturamento. Dentre as contas analisadas $91,42 \%$ receberam ajustes, sendo $57,59 \%$ positivos, com média de $\mathrm{R} \$ 1.340,75(\mathrm{DP} \pm 2.502,93)$ e $33,83 \%$ negativos, com média de $\mathrm{R} \$$ $1.571,58(\mathrm{DP} \pm 5.990,51)$. O total de glosas dos itens analisados por enfermeiras ou por médicos, bem como em itens examinados por ambos, correspondeu em média a $\mathrm{R} \$ 380,51(\mathrm{DP} \pm 1.533,05)$. As glosas referentes aos itens conferidos por médicos perfizeram um total médio de $\mathrm{R} \$ 311,94(\mathrm{DP} \pm 646,86)$ e as glosas referentes aos itens conferidos por enfermeiras de $R \$ 255,84(D P \pm 1.636,76)$. $O$ excesso de ajustes evidenciou a deficiência e a falta de uniformidade dos registros da equipe de saúde. Considera-se que esta pesquisa representa a possibilidade de avanço no conhecimento acerca da auditoria de contas hospitalares à medida que investigou 0 processo de pré-análise realizado por enfermeiras e médicos auditores.

Descritores: Cardiologia, Auditoria, Documentação e Faturamento. 


\begin{abstract}
Guerrer GFF. Audit of Accounts in a Specialized Cardiology and Pneumology Teaching Hospital: a case study [dissertation]. São Paulo: School of Nursing, University of São Paulo; 2012.

Hospitals that provide services to health plan companies invest in the audit of accounts aiming to provide adequate remuneration of their service. The pre-analysis of accounts is when the audit team makes corrections to determine the foundations for billing the procedures, and to avoid disallowances and revenue losses. From that perspective, the objective of the present study was to identify the patient bill items that were most corrected after being submitted to pre-analysis; identify the impact of those corrections on the revenue of accounts that were analyzed by the hospital's audit team (physicians and nurses) after the pre-analysis; calculate the revenue that the referred team is able to correct, and identify the disallowances related to the items they checked. This exploratory, descriptive, retrospective case study was performed at the Heart Institute (InCor) of the University of São Paulo School of Medicine Clinics Hospital (HCFMUSP) using a quantitative approach. The study included a total of 2,613 accounts that had been pre-analyzed by the InCor audit team in the period spanning January to December of 2011. The revenue was concentrated in four $(62.9 \%)$ of the 34 credited health plan companies. There was predominance by company $\mathrm{A}(27.6 \%)$, but the highest mean value per account was obtained by company $D$, with $R \$ 19,187.50$. The items most often included in the accounts by the nurses were gauzes (90.5\%); hospitalization materials (85\%) and nursing care (83.2\%). Hemodynamics materials, with a mean $R \$ 1,055.90$ (SD \pm 3,953.45); gauzes, with a mean $\mathrm{R} \$ 707.91$ (SD \pm 843.95), and equipment, with a mean $R \$ 689.42$ ( $S D \pm 1145.20$ ) were the items with the strongest financial impact on the corrections. The items most often excluded from the accounts referred to hospitalization medications (41.2\%); equipment (28\%) and nursing care (17\%). Regarding the negative changes, the items with the strongest financial impact were Hemodynamics materials, with a mean $R \$ 3,860.15$ ( $S D \pm 15,220.80)$; medications used in Hemodynamics, with a mean $\mathrm{R} \$ 1,983.04$ ( $S D \pm 8,324.42$ ), and gauzes, with a mean $R \$ 1,048.51$ ( $S D \pm 3,025.53$ ). Nurses included a total of $R \$ 1,877,168.64$, and excluded $R \$ 1,155,351.36$, while physicians included $R \$ 563,927.46$ and excluded $R \$ 657,190.19$. If the pre-analysis had not been performed, there would have been a revenue loss of $\mathrm{R} \$ 628,554.55$. Of all the accounts submitted to analysis, $91.42 \%$ were corrected, of which $57.59 \%$ were positive, with a mean $R \$$ $1,340.75(\mathrm{SD} \pm 2,502.93)$ and $33.83 \%$ were negative, with a mean $\mathrm{R} \$ 1,571.58$ (SD \pm $5,990.51)$. Regarding disallowances, the final sum considering the items analyzed by nurses, physicians or both corresponded to a mean $\mathrm{R} \$ 380.51$ ( $\mathrm{SD} \pm 1,533.05$ ). The disallowances referring to the items analyzed by physicians added up to a mean total of $R \$ 311.94$ ( $S D \pm 646.86$ ), and those referring to the items analyzed by nurses to $\mathrm{R} \$ 255.84$ (SD $\pm 1,636.76$ ). The excessive number of corrections showed the lack of uniformity in the records made by the health team. This study represents a possibility of knowledge advancement regarding the audit of hospital accounts as it investigated the pre-analysis process performed by nurses and physicians.
\end{abstract}

Descriptors: Cardiology; Audit; Documentation; Billing. 


\section{LISTA DE FIGURA}

FIGURA 1- Fluxograma do processo de formação da conta hospitalar, São

Paulo - 2011. 


\section{LISTA DE TABELAS}

TABELA 1 - Caracterização das contas hospitalares submetidas à pré-análise pela equipe de auditoria da USS - InCor HCFMUSP, São Paulo 2011.

TABELA 2 - Distribuição das contas hospitalares por operadoras de planos de saúde submetidas à pré-análise pela equipe de auditoria da USS

- InCor HCFMUSP, São Paulo - 2011.

TABELA 3 - Distribuição dos valores médios das contas hospitalares das operadoras de planos de saúde predominantes - InCor

HCFMUSP, São Paulo - 2011.

TABELA 4 - Distribuição das diárias nas contas hospitalares auditadas - InCor HCFMUSP, São Paulo - 2011.

TABELA 5 - Distribuição da inclusão dos Itens componentes das contas hospitalares auditados por enfermeiras da USS - InCor HCFMUSP, São Paulo - 2011.

TABELA 6 - Distribuição da exclusão dos Itens componentes das contas hospitalares auditados por enfermeiras da USS - InCor HCFMUSP, São Paulo - 2011.

TABELA 7 - Distribuição média dos ajustes realizados nas contas hospitalares pela equipe de auditoria da USS - InCor HCFMUSP, São Paulo 2011.

TABELA 8 - Distribuição média das glosas recebidas pela equipe de auditoria da USS - InCor HCFMUSP, São Paulo - 2011.

TABELA 9 - Distribuição das glosas dos itens componentes das contas hospitalares, auditados por enfermeiras. InCor HCFMUSP, São Paulo - 2011

TABELA 10 - Distribuição dos dias de permanência da conta hospitalar na UFA e USS do InCor HCFMUSP até a sua apresentação às fontes pagadoras, São Paulo- 2012. 


\section{LISTA DE GRÁFICOS}

Gráfico 1 - Faturamento relativo aos ajustes positivo e negativo realizados nas contas hospitalares pela equipe de auditoria da USS - InCor HCFMUSP, São Paulo - 2011. .45

Gráfico 2 - Faturamento total relativo aos ajustes positivo e negativo realizados nas contas hospitalares pela equipe de auditoria da USS - InCor HCFMUSP, São Paulo - 2011. 


\section{LISTA DE APÊNDICES E ANEXOS}

APÊNDICE I - Instrumento de Coleta de Dados .............................................. 72

APÊNDICE II - Agrupamento dos Diagnósticos médicos em especialidades...........75

ANEXO I - Autorização junto a Diretoria da USS .................................................. 80

ANEXO II - Aprovação pelo Comitê de Ética em Pesquisa da Escola de

Enfermagem da Universidade de São Paulo 


\section{SUMÁRIO}

1 INTRODUÇÃO

1.1 AS ENFERMEIRAS, O GERENCIAMENTO DE CUSTOS E O FATURAMENTO HOSPITALAR ..................................................... 16

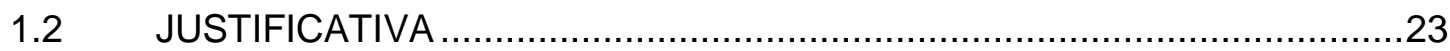

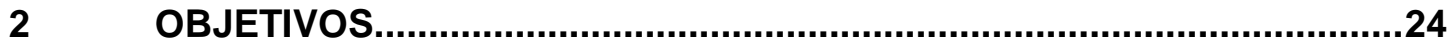

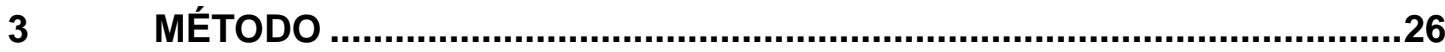

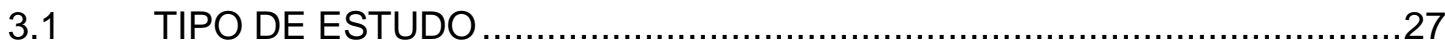

3.2 LOCAL DE ESTUDO

3.2.1 O Processo de faturamento do Hospital em estudo...................................28

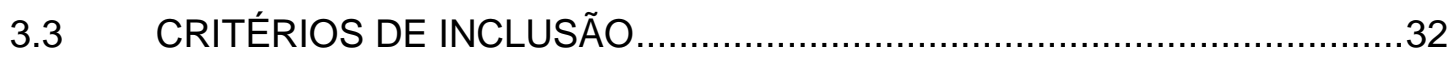

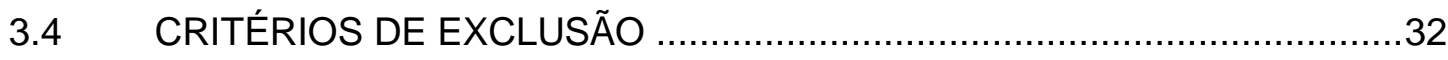

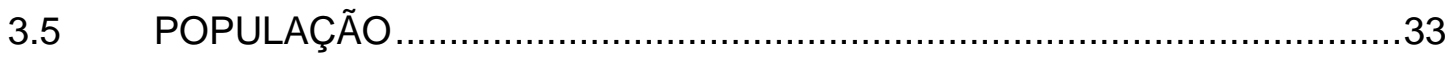

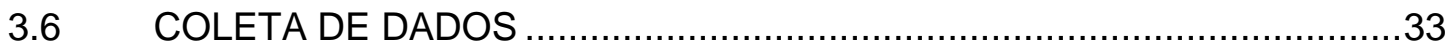

3.6.1 Protocolo para realização do estudo de caso sobre auditoria de contas em um Hospital de Ensino Especializado em Cardiologia e Pneumologia .................................................................................... 33

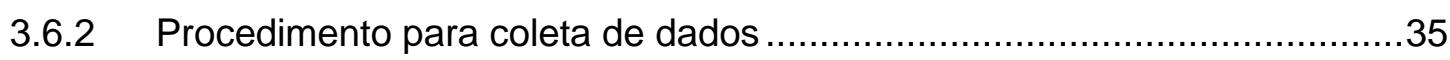

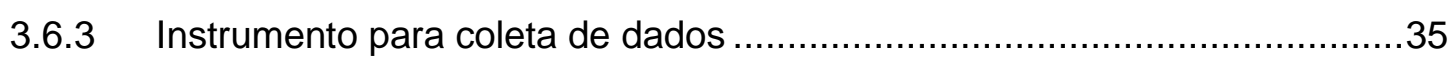

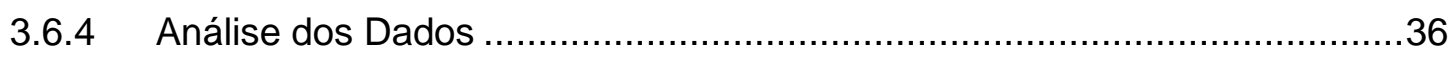

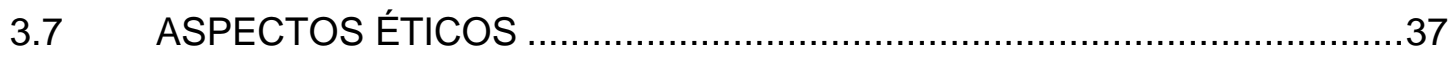

4 APRESENTAÇÃO DOS RESULTADOS ..............................................38

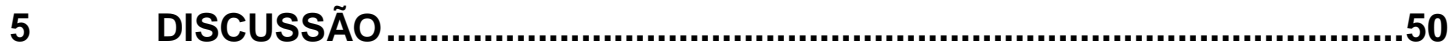

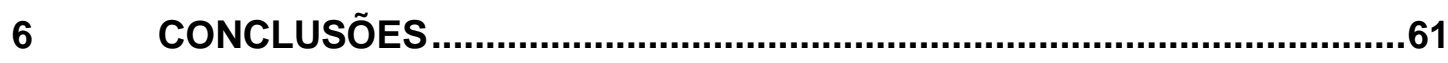

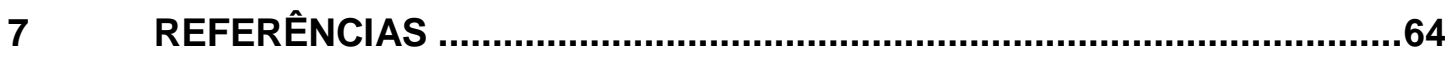

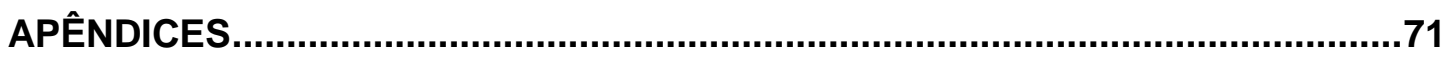

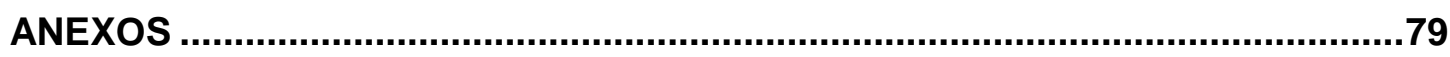


1 INTRODUÇÃO 
O financiamento das políticas de saúde tem-se destacado como relevante do ponto de vista econômico há pouco tempo, pois até a década de 30 as funções do Estado eram pequenas e o financiamento da saúde ocupava apenas ações de saneamento e combate de endemias. A assistência médica passou a fazer parte das atribuições financeiras do Estado após a segunda Guerra Mundial ${ }^{1}$.

A estruturação da saúde privada no Brasil teve inicio com o Instituto de Aposentadorias e Pensões. Este Instituto representava diversas categorias de trabalhadores urbanos, que compravam a prestação de serviços de consultórios médicos ou de estabelecimentos hospitalares. $\mathrm{Na}$ década de 40 surgiram as caixas de assistência, que beneficiavam empregadores de algumas empresas por meio de empréstimo e reembolsos pela utilização dos serviços de saúde externos à Previdência Social. Em 1950 com a vinda de empresas estatais e multinacionais, surgiram os sistemas médicos próprios, que assistiam seus funcionários de forma direta. Com isso aumentou o credenciamento de prestadores de serviços privados de saúde pelo financiamento de grupos médicos que gradativamente foram se transformando em empresas médicas².

Atualmente o Brasil é a sexta economia do mundo, porém os gastos com saúde se equiparam a realidade de países subdesenvolvidos. É um dos poucos países do mundo onde a população paga mais de $50 \%$ dos gastos com saúde, sendo a média mundial de 40\%. Em 2009 as despesas públicas per capita, com consumo de bens e serviços de saúde foram de $R \$$ 645,27 e as despesas per capita privadas foram de $\mathrm{R} \$ 835,65$ nesse ano, comprovando que a população gasta mais do que o governo para ter acesso a remédios, consultas, planos de saúde, hospitais e exames ${ }^{3}$. De acordo com a Organização mundial da Saúde (OMS) o Brasil investe aproximadamente $9 \%$ do seu PIB em saúde enquanto que os Estados Unidos da América (EUA) 16,2\% ${ }^{4}$.

Com a globalização e o recente cenário político financeiro brasileiro, o setor de saúde tem procurado novas alternativas para a gestão, focalizando a necessidade das organizações adaptarem-se a um mercado cada vez mais competitivo ${ }^{5}$. 
O progresso tecnológico na área da saúde, com a introdução de novos equipamentos, novos métodos diagnósticos e novos processos terapêuticos, tem provocado o crescimento dos gastos, afetando a economia de vários países ${ }^{6-7}$.

Esse crescimento relativo pode se tornar insustentável em longo prazo, havendo então a necessidade de se estudar estratégias de controle dos custos ${ }^{8}$.

A elevação dos custos tem se constituído em objeto de atenção por parte dos gestores hospitalares, profissionais de saúde e das fontes pagadoras da assistência, quer seja o Sistema Único de Saúde (SUS) ou o Sistema Suplementar (SS), por meio das operadoras de planos e convênios ${ }^{9}$.

Constata-se que os hospitais da rede pública têm enfrentado dificuldades para gerirem recursos escassos decorrentes da diminuição dos gastos federais com saúde, frente às demandas crescentes da população ${ }^{9}$.

Entretanto, o SS também tem enfrentado grandes dificuldades financeiras, sem poder repassar seus aumentos de custos automaticamente para os preços em virtude, principalmente, de fatores relacionados à competitividade do mercado, à pressão da sociedade e dos planos de saúde e a certo controle de preços do governo ${ }^{10}$.

A determinação dos custos hospitalares pode auxiliar a definição de preço e venda de serviços, a tomada de decisões para aquisição de novos investimentos e tecnologias, o estabelecimento dos custos e dos lucros de um dado período, calcular valor e custo de estoque de materiais e medicamentos para formação do preço e venda ${ }^{11}$.

Percebe-se que as organizações de saúde são obrigadas a suprir o crescimento da demanda com o aumento da prestação da assistência ao paciente, porém com a necessidade de redução de custos imposta pelos níveis de produção dos seus setores e pela quantidade de recursos financeiros disponíveis ${ }^{12}$.

Assim, conhecer os custos dos serviços de saúde permite identificar os pontos críticos da organização que precisam ser reduzidos por 
meio do controle dos gastos, eliminação do desperdício, alcance da eficiência e preservação da qualidade no atendimento ${ }^{13}$.

Nesta direção os profissionais de saúde têm procurado utilizar ferramentas gerenciais que os auxiliem na obtenção de eficiência e eficácia quanto à utilização de recursos que lhes são oferecidos ${ }^{14}$.

\subsection{AS ENFERMEIRAS, O GERENCIAMENTO DE CUSTOS E O FATURAMENTO HOSPITALAR}

De acordo com Martins ${ }^{15}$ custos são definidos como "gastos relativos à bem ou serviço utilizado na produção de outros bens de serviços".

Para Horngren, Foster, Datar ${ }^{16}$ gerenciamento de custos corresponde ao conjunto de ações que os gestores tomam para satisfazer os clientes enquanto, continuamente, reduzem e controlam os custos.

$\mathrm{Na}$ gestão de custos hospitalares, Matos ${ }^{17}$ afirma que é considerado o melhor gestor quem conhece, profundamente, as atividades desenvolvidas na unidade e não quem apenas reúne os conceitos relacionados á contabilização dos custos.

As enfermeiras que ocupam posições gerenciais, em diversos setores hospitalares, têm um papel importante à medida que em seu cotidiano se preocupam com os custos de maneira a fundamentar seus argumentos em relação à obtenção e manutenção recursos para a assistência de enfermagem ${ }^{14}$.

Estas profissionais de saúde estão representadas em todos os serviços hospitalares e por trabalharem muito próximas à clientela, podem avaliar a assistência prestada, bem como fazer parte das discussões financeiras e políticas das instituições ${ }^{10}$.

Francisco, Castilho ${ }^{10}$ conceituam o gerenciamento de custos em enfermagem como um processo administrativo que visa à tomada de decisão das enfermeiras em relação à eficiente racionalização na alocação de recursos disponíveis e limitados, com o objetivo de alcançar resultados coerentes às necessidades de saúde da clientela $e$ as finalidades institucionais. Para tanto, enfatizam que as enfermeiras necessitam 
compreender um conjunto de princípios e conhecimentos de análise econômica que viabilizem a escolha de decisões mais convenientes.

Ao analisar a participação das enfermeiras no gerenciamento de custos de organizações hospitalares Mendes $^{18}$ identificou que $89 \%$ não participam da elaboração do orçamento, 91\% não possuem acesso a informações necessárias para custeio e 40\% não possuem conhecimento geral sobre custos demonstrando a necessidade da utilização de ferramentas gerenciais em custos e do aprimoramento das enfermeiras sobre o assunto.

Castilho, Fugulin, Gadzinski ${ }^{19}$ ressaltam que as enfermeiras podem melhorar o desempenho da instituição de saúde, bem como das unidades em que trabalham se conhecerem os modos de custeio, identificando e monitorando os elementos e as etapas do processo que aumentam os custos e que podem ser cortados sem prejuízo da qualidade e sem comprometer o atendimento da demanda.

Contudo, para que o gerenciamento de custos seja efetivo é necessário o envolvimento não somente dos gerentes das organizações hospitalares, mas também dos componentes da equipe multiprofissional ${ }^{20}$.

Então a racionalização de custos deve ser fundamentada em um conjunto de ações que influenciem a mudança de comportamento dos profissionais. Nesta direção, é indispensável o conhecimento de conceitos, tais como, custos, metodologia de custeio, formação de controle de custos com a finalidade de diminuição das perdas, controle de desperdícios assim como a execução de procedimentos com alto rigor técnico e consciência da utilização correta dos materiais ${ }^{21}$.

Margarido e Castilho ${ }^{14}$ afirmam que as enfermeiras começam a se preocupar em obter informações sobre custos a fim de fundamentar seus argumentos em relação à obtenção e manutenção de recursos para a assistência de enfermagem e conhecer os custos reais do seu trabalho.

O pagamento da assistência de enfermagem está incluído nas diárias e taxas de procedimentos. As diárias compreendem os serviços básicos de enfermagem como exemplos, banho, alimentação, higienização, encaminhamento de pacientes, medidas de peso e altura. Já os 
procedimentos que podem ser cobrados, tais como, retirada de pontos, alimentação parenteral, curativos, enteroclisma, dependem de negociações realizadas entre o prestador de serviço e operadoras de planos de saúde ${ }^{22}$.

De acordo com Aburdene, Naisbitt ${ }^{23}$ as enfermeiras são responsáveis por 40 a $50 \%$ do faturamento dos hospitais, pois seu trabalho melhora a qualidade e os custos da assistência.

Para Sandroni ${ }^{24}$ faturamento refere-se ao "conjunto de recebimentos expressos em unidades monetárias, obtidos por uma empresa com a venda de bens ou serviços em determinado período".

Ao calcular o faturamento gerado pela equipe de enfermagem, em uma Unidade de Terapia Intensiva (UTI) de um hospital particular, Zunta, Castilho ${ }^{25}$ demonstraram que ela foi responsável por $15,1 \%$ do faturamento total, sendo $11,3 \%$ proveniente da prescrição de enfermagem e 3,8\% da prescrição médica. As autoras ressaltaram que esse percentual, na realidade, seria maior, uma vez que muitos outros procedimentos estariam incluídos nas diárias e taxas de sala, citando como exemplos a realização de banho e o auxílio na alimentação.

Estudo realizado em uma UTI Geral estabeleceu a relação entre o custo-padrão e a quantidade de procedimentos decorrentes da prescrição médica e de enfermagem, durante os primeiros dez dias de internação dos pacientes. Mostrou que as prescrições das enfermeiras foram responsáveis, por aproximadamente, $70 \%$ do valor em reais concentrando-se no primeiro e segundo dia de internação ${ }^{21}$.

Cabe salientar que a falha de registros de materiais e medicamentos utilizados tanto pela equipe de enfermagem como médica geram erros em cobranças e, consequentemente, prejuízo financeiro às instituições de saúde ${ }^{26}$.

Um estudo retrospectivo da avaliação qualitativa das anotações de enfermagem mostrou que $99,5 \%$ dos prontuários analisados possuíam anotações de enfermagem. Porém, destas apenas $2,4 \%$ estavam completas, $26,7 \%$ foram consideradas ruins, $64,6 \%$ regulares e $8,7 \%$ boas ${ }^{27}$. 
Para assegurar a qualidade dos serviços prestados aos clientes grandes empresas têm-se preocupado em utilizar a auditoria, de forma contínua, visto que estes estão cada vez mais convictos de seus direitos ${ }^{28}$.

$\mathrm{Na}$ saúde a auditoria surgiu com a finalidade de avaliar a qualidade da assistência prestada ao paciente, mas a competitividade, o avanço tecnológico e os tratamentos cada vez mais dispendiosos despertaram nos profissionais que atuam nesta área, a necessidade de desenvolver a visão financeira contábil ${ }^{29}$.

Motta $^{30}$ define auditoria de enfermagem como a avaliação da qualidade da assistência prestada ao cliente por meio da análise de prontuário e da verificação da compatibilidade entre o procedimento realizado e os itens componentes da conta hospitalar cobrados. Segundo este autor a auditoria pode ser realizada das seguintes formas:

- Pré-auditoria ou Auditoria prospectiva: avaliação dos procedimentos médicos antes de sua realização. Como exemplo, a emissão de parecer pelo médico da operadora de saúde sobre um determinado tratamento ou procedimento cabendo a ele, por meio de seu conhecimento sobre contratos e legislação, recomendar ou não a realização;

- Auditoria concorrente ou pró-ativa: análise pericial ligada ao tratamento ou procedimento ao qual o paciente será submetido durante a sua internação;

- Auditoria de contas hospitalares, retrospectiva ou de revisão de contas: análise pericial dos procedimentos médicos realizados com ou sem apreciação do prontuário. Como exemplo, a análise de contas interna ou externamente após seu fechamento, ou seja, alta do paciente ${ }^{30}$.

A atuação da enfermeira nos serviços de auditoria tem se fundamentado no seu conhecimento das práticas assistenciais, administrativas e gerenciais, bem como na sua experiência em incrementar os recursos físicos e materiais, planejar e executar o trabalho, considerando o custo benefício para o paciente, hospital e comprador de serviços de saúde ${ }^{31}$. 
De acordo com Souza, Moura e Flores ${ }^{32}$ a auditoria não consiste apenas no preenchimento de formulários, mas sim em uma análise sistemática de ações e utilização de estratégias pedagógicas para que os auditores, juntamente com a equipe auditada, possam produzir mudanças de atitudes e comportamentos melhorando a qualidade da assistência e diminuindo erros.

Nesse sentido, para Scarparo et. al. ${ }^{33}$ a auditoria é um elemento fundamental para mensurar a qualidade da assistência, bem como um instrumento norteador do processo de educação permanente. A padronização da assistência de enfermagem, condutas e rotinas nortearia a avaliação dos processos e resultados facilitando a auditoria.

As ações de enfermagem interferem diretamente nos resultados da auditoria de contas, pois os processos assistenciais geram receita por meio dos registros das ações realizadas ${ }^{34}$.

Para a auditoria de contas hospitalares o prontuário clínico é um dos principais instrumentos de trabalho, pois por meio dele se comprova a realização dos procedimentos para subsidiar a cobrança junto às fontes pagadoras. Na Sistematização da Assistência de Enfermagem (SAE), por meio da prescrição e anotação de enfermagem, encontram-se justificativas à cobrança das taxas e serviços que não estão inclusos na diária.

Porém, as anotações de enfermagem freqüentemente são registradas de forma incompleta e inadequada comprometendo os aspectos éticos e legais desta documentação e, em algumas instituições, estão geralmente voltadas apenas ao cumprimento dos itens da prescrição médica $^{34}$.

Salienta-se que grande parte do pagamento de materiais, medicamentos e procedimentos é vinculada aos registros de enfermagem que, na maioria das vezes, são inconsistentes, ilegíveis e subjetivos ocasionando a glosa de itens do faturamento ${ }^{35}$.

Ao realizar auditoria interna a enfermeira pode detectar falhas $e$ para que estas não se tornem recorrentes é fundamental o estabelecimento de parceria com o Serviço de Educação Continuada determinando um plano de ação compreendendo reeducação, treinamentos, conscientização, 
valorização dos pontos positivos, reflexão sobre os negativos e orientação contínua de toda a equipe ${ }^{36}$.

Zunta et.al. ${ }^{37}$ ressaltam que é de fundamental importância que a equipe de enfermagem possua conhecimento sobre os custos dos materiais, equipamentos e procedimentos realizados o que pode melhorar os registros da assistência prestada e conseqüentemente o diminuir as perdas de faturamento e glosas hospitalares.

As perdas correspondem ao prejuízo financeiro decorrente da falta de cobrança de itens utilizados durante a internação do paciente, isto é, que são comprovados em documentos, tais como invólucros e notas fiscais, e registrados em prontuário, mas que não são devidamente lançados para efeito de faturamento.

Glosa significa o cancelamento ou recusa parcial ou total de orçamento, conta, verba por serem considerados ilegais ou indevidos, refere-se aos itens que o auditor do plano de saúde não considera cabível ao pagamento ${ }^{38}$.

As glosas podem ser classificadas como administrativas ou técnicas. As primeiras são decorrentes de falhas operacionais no momento da cobrança, falta de interação entre o plano de saúde e o prestador de serviço que estão vinculadas as clausulas contratuais. As segundas são resultantes da equipe de enfermagem ou médica e estão vinculadas a falta de justificativas ou embasamento que se apliquem a indicação de determinado procedimento, bem como a falta de anotações de enfermagem durante a assistência prestada ao cliente ${ }^{38}$.

Ressalta-se que a prática de glosar itens do faturamento das contas constitui-se em perda significativa para o orçamento das instituições. Dessa forma, quando elas têm os valores dos serviços prestados glosados pelas operadoras de planos de saúde, podem munir-se de recursos de glosas, a fim de recuperar suas perdas econômicas.

Estudo realizado por Rodrigues, Perroca, Jericó ${ }^{35}$ objetivando identificar as glosas e sua incidência demonstrou que $86 \%$ dos itens glosados eram materiais (com maior representatividade relacionada a compressas de gaze, luvas cirúrgicas e material de infusão) e 11,6\% 
medicamentos (soluções para diluição de medicamentos, solução de clorexidine e o medicamento dimeticona).

A análise das glosas em um hospital oftalmológico evidenciou que $68,8 \%$ corresponderam a medicamentos e $31,1 \%$ a materiais. As glosas dos medicamentos foram classificadas como técnicas e a de materiais como técnicas e administrativas ${ }^{39}$.

Ao desenvolver um estudo em uma unidade de urologia de um hospital privado de médio porte, Ferreira, Braga, et. al. ${ }^{40}$ identificaram que $53 \%$ das glosas referiram-se a medicamentos, 24\% a taxas e aluguéis e $23 \%$ a materiais. Estas glosas ocorreram por falta de anotação e checagem de enfermagem, assim como pela forma ilegível e incompleta das evoluções de enfermagem que não forneciam as informações necessárias e geravam dúvidas em relação ao tratamento aplicado.

Galvão $^{41}$ refere que o volume de perdas em medicamentos e materiais, principais fontes de lucratividade dos hospitais, é crescente e pouco controlado e a auditoria de enfermagem pode realizar um trabalho pró-ativo em relação a este aspecto.

Contudo Scarparo, Ferraz ${ }^{29}$ afirmam que na atualidade, o papel da enfermagem na auditoria de contas, restringe-se a comprovação de pagamento de contas hospitalares, revendo glosas, por meio de relatório técnico, e realizando negociação entre representantes do hospital e convenio, cumprindo apenas a finalidade institucional que está pautada nos enfoques empresariais e mercadológicos.

Buzatti, Chianca ${ }^{26}$ destacam que o serviço de auditoria sempre esteve associado ao controle administrativo e financeiro das organizações. Entretanto, a auditoria deve ser considerada também como uma atividade educativa assim os profissionais precisam promover ações enfatizando as causas que levaram ao erro ao invés de buscar apenas o responsável pela falha ${ }^{32}$.

Com a finalidade de educar e acompanhar os colaboradores de enfermagem quanto aos registros realizados em prontuário, a gerência de enfermagem e o Serviço de Educação Continuada de uma instituição privada, geral e de grande porte em São Paulo, criaram o cargo de 
enfermeira de faturamento hospitalar. Objetivavam melhorar as anotações de enfermagem, diminuindo assim as divergências entre as informações contidas nos prontuários e nas contas hospitalares Após treinamento da equipe de enfermagem do Centro Cirúrgico a respeito do faturamento constataram que o indicie de divergências que era de $38,2 \%$ diminuiu para $15,8 \%{ }^{37}$.

Nesta perspectiva, concorda-se com outros autores que a auditoria de enfermagem deve ser utilizada como instrumento de qualidade, identificando deficiências da assistência e fornecendo dados para melhoria dos programas e da qualidade do cuidado ${ }^{35}$.

\subsection{JUSTIFICATIVA}

Atuando como enfermeira auditora de contas hospitalares em um hospital de nível terciário especializado em cardiologia e pneumologia, a autora deste estudo observou que durante a pré-análise das contas hospitalares frequentemente eram detectadas ausências de registros que fundamentassem adequadamente, a cobrança a partir do procedimento realizado.

Considerou então a necessidade de avaliar as glosas e as perdas do faturamento por meio da pré-análise das contas hospitalares, ou seja, a conferência entre os itens que compõe a conta hospitalar do paciente (diárias, honorários médicos e de enfermagem, exames laboratoriais, hemoterápicos, órteses, próteses, equipamentos, materiais, gases medicinais e medicamentos) com os registros da equipe multidisciplinar no prontuário antes da sua apresentação às fontes pagadoras.

Pergunta da pesquisa:

Qual a percentagem do faturamento que os auditores, da Instituição em questão, ao realizar a pré-análise, conseguem ajustar nas contas dos pacientes internados? 
2 OBJETIVOS 
$\checkmark$ Verificar os itens componentes das contas dos pacientes internados em um hospital de nível terciário especializado em cardiologia e pneumologia, conferidos por enfermeiros, que mais recebem ajustes no momento da pré-análise;

$\checkmark$ Identificar o impacto dos ajustes no faturamento das contas analisadas pela equipe de auditoria após a pré-analise;

$\checkmark$ Calcular o faturamento que a equipe de auditoria consegue ajustar nas contas dos pacientes internados;

$\checkmark$ Identificar as glosas nas contas dos pacientes internados relacionadas aos itens conferidos pela equipe de auditoria. 
3 MÉTODO 


\subsection{TIPO DE ESTUDO}

Estudo exploratório, descritivo, retrospectivo, de abordagem quantitativa na modalidade de estudo de caso, envolvendo as contas dos pacientes internados por convênios e particulares em um hospital de nível terciário especializado em cardiologia e pneumologia.

A escolha pelo estudo de caso fundamenta-se no fato dele "investigar um fenômeno contemporâneo em profundidade e em seu contexto de vida real, especialmente quando os limites entre o fenômeno e o contexto não são claramente evidentes" ${ }^{42}$.

\subsection{LOCAL DE ESTUDO}

O estudo foi desenvolvido no Instituto do Coração (InCor) do Hospital das Clínicas da Faculdade de Medicina da Universidade de São Paulo (HCFMUSP). Trata-se de um Hospital escola de nível terciário especializado em Cardiologia e Pneumologia que possui aproximadamente 500 leitos destinados ao atendimento de pacientes com tratamento financiado por três fontes pagadoras: o SUS com 390 leitos, empresas de SS (operadoras de planos de saúde) e Particulares com 110 leitos dos quais a taxa de ocupação correspondeu a aproximadamente 60\% no ano de 2011 .

Em 1999 foi instituída no InCor a Unidade de Saúde Suplementar (USS) com o objetivo de obter a adequada remuneração das diárias, dos honorários profissionais, equipamentos, materiais, medicamentos, hemoterápicos e exames complementares referentes ao atendimento de pacientes provenientes de operadoras de planos de saúde e particulares por meio da auditoria de contas médicas e apresentação destas as fontes pagadoras.

A equipe da USS é composta por cinco auditores (dois médicos e três enfermeiras), dois analistas de contas médicas, uma digitadora, cinco auxiliares administrativos, uma supervisora de auditoria de contas médicas e recuso de glosas e dois analistas de glosas. 
O Hospital dispõe de um sistema eletrônico, denominado Sistema Integrado de Informações do InCor (Si3), que fundamenta o processo de faturamento ao possibilitar a documentação do cuidado prestado ao paciente durante toda sua internação (Sistematização da Assistência de Enfermagem -SAE; anamnese, diagnóstico, evolução e prescrição médica; registros de outros profissionais da equipe de saúde; exames diagnósticos; procedimentos; materiais; medicamentos; gazes; equipamentos; diárias; honorários; taxas; entre outras).

\subsubsection{O Processo de faturamento do Hospital em estudo}

O processo de formação de uma conta inicia-se na Unidade de Faturamento (UFA) assim que o paciente é admitido em umas das unidades de internação do InCor.

Na UFA é aberto o prontuário contábil onde serão colocadas todas as notas de débito dos itens utilizados, guias e autorizações, bem como invólucros com as etiquetas contendo a descrição do material, número da nota fiscal, fornecedor, o fabricante, o código Agência Nacional de Vigilância Sanitária (ANVISA), lote e série dos materiais de alto custo que foram utilizados durante a internação do paciente. Isto se faz necessário para comprovar que o Hospital não realiza o reprocessamento de materiais de alto custo.

Visando facilitar a conferência das contas hospitalares e minimizar o tempo para sua apresentação à fonte pagadora (operadora de planos de saúde) estabeleceu-se, na Instituição, que para as internações de longa permanência seriam preparadas contas parciais a cada 10 dias. Assim, como exemplo, se o paciente ficar internado por quinze dias terá duas contas, uma administrativa referente a dez diárias e outra final relativa a cinco diárias. No caso de pacientes particulares as contas são emitidas a cada quatro dias, e realizada a auditoria concorrente na unidade em que o paciente está internado, pois a tabela de cobrança de taxas e serviços é extensa. Esta medida facilita a pré-análise e a apresentação das contas aos 
pacientes que no momento da alta hospitalar terão conhecimento da quantia a ser paga.

Na UFA há outra forma de cobrança, denominada pacote, que é regida por contratos firmados entre o InCor e as operadoras de planos de saúde. Nela é estabelecido um preço fechado por internação para realização de um dado procedimento. Entretanto, caso ocorram complicações clínicas torna-se necessária à abertura das contas, anteriormente citadas.

Em síntese a UFA emite uma conta prévia à USS a cada 10 dias (no caso de operadoras de plano de saúde), quatro dias (particulares) ou quando o paciente receber alta antes de completar esses períodos, anexando junto ao prontuário contábil, o seu prontuário clinico para que se realize a auditoria.

No InCor, o fluxo mensal corresponde, em média, a 300 contas divididas em três subgrupos: clínico, cirúrgico e de procedimentos diagnósticos e/ou terapêuticos realizados no Serviço de Hemodinâmica. As contas de pacientes que inicialmente realizaram procedimentos nesse Serviço e posteriormente foram encaminhados à cirurgia, são classificadas como do subgrupo cirúrgico.

Os médicos são responsáveis pela conferência dos seguintes itens: diárias, taxas administrativas, exames (como exemplos: patologia clínica, diagnóstico por imagem e métodos gráficos), hemoterapia, honorários médicos, fisioterapia (motora e respiratória), verificação das autorizações das operadoras de plano de saúde para a realização de procedimentos, dos códigos de procedimentos que devem ser preenchidos conforme as tabelas previamente acordadas e utilização de materiais de alto custo.

Cabe as enfermeiras a análise dos itens componentes das contas hospitalares acordados conforme o contrato estabelecido com as operadoras de planos de saúde:

- Serviços de enfermagem - cuidados de enfermagem realizados aos pacientes durante o período de internação (punções venosas; administração de medicamentos sub-cutâneos e/ou endovenosos; controle de diurese; curativos; enteroclisma; administração de dieta 
por via enteral; realização de orientações de enfermagem; cateterismo vesical; tricotomia; retirada de pontos, drenos, fios e cateteres; instalação de hemodiálise, inalação, controle de débito cardíaco, entre outras);

- Equipamentos - inclusão de taxa referente à utilização de equipamentos, por dia ou hora, como exemplos, bomba de infusão, respirador, transdutor, polígrafo, telemetria, monitorização de pressão não invasiva marcapasso temporário, balão intra-aórtico, oxímetro;

- Gases - oxigênio, ar comprimido e oxido nítrico de acordo com o tempo de utilização;

- Materiais e medicamentos - como exemplos, agulhas, seringas, luvas, equipos, torneirinhas, gaze, fármacos vasoativos, antibióticos, soluções para diluição, eletrólitos.

Os auditores conferem todos os itens das contas prévias juntamente com o prontuário clinico do paciente e registram os dados em planilhas eletrônicas distintas que possuem itens comuns e específicos, conforme apresentado a seguir (Quadro 1):

Quadro 1 - Planilhas eletrônicas utilizadas pela equipe de auditoria que integram o banco de dados da USS do InCor.

\begin{tabular}{|l|c|l|}
\hline $\begin{array}{c}\text { Itens comuns à } \\
\text { equipe de auditoria }\end{array}$ & $\begin{array}{c}\text { Itens registrados por } \\
\text { médicos }\end{array}$ & \multicolumn{1}{|c|}{$\begin{array}{c}\text { Itens registrados por } \\
\text { enfermeiras }\end{array}$} \\
\hline Registro Hospitalar & Sexo & $\begin{array}{l}\text { Serviço de enfermagem: pré e } \\
\text { pós-análise, ajustes glosas. }\end{array}$ \\
\hline Nome & Idade & $\begin{array}{l}\text { Equipamentos: pré e pós- } \\
\text { análise, ajustes, divergências e } \\
\text { glosas. }\end{array}$ \\
\hline $\begin{array}{l}\text { Operadoras de } \\
\text { plano de saúde }\end{array}$ & Óbito & $\begin{array}{l}\text { Gases: pré e pós-análise, } \\
\text { ajustes e glosas. }\end{array}$ \\
\hline $\begin{array}{l}\text { Data de início da } \\
\text { conta }\end{array}$ & Diagnóstico médico & $\begin{array}{l}\text { Materiais utilizados na } \\
\text { internação: pré e pós-análise, } \\
\text { ajustes, divergências e glosas. }\end{array}$ \\
\hline Data de fim da conta & $\begin{array}{l}\text { Diárias (apartamento, UTI, } \\
\text { total) }\end{array}$ & $\begin{array}{l}\text { Medicamentos utilizados na } \\
\text { internação: pré e pós-análise, } \\
\text { ajustes e glosas }\end{array}$ \\
\hline
\end{tabular}




\begin{tabular}{|c|c|c|}
\hline $\begin{array}{l}\text { Itens comuns à } \\
\text { equipe de auditoria }\end{array}$ & $\begin{array}{l}\text { Itens registrados por } \\
\text { médicos }\end{array}$ & $\begin{array}{l}\text { Itens registrados por } \\
\text { enfermeiras }\end{array}$ \\
\hline $\begin{array}{l}\text { Valor inicial da conta } \\
\text { enviada pela UFA }\end{array}$ & Valor final total da conta & $\begin{array}{l}\text { Materiais utilizados no Centro } \\
\text { Cirúrgico: pré e pós-análise, } \\
\text { ajustes, divergências e glosas. }\end{array}$ \\
\hline \multirow{8}{*}{$\begin{array}{l}\text { Valor da conta } \\
\text { ajustado }\end{array}$} & Glosa final total & $\begin{array}{l}\text { Medicamentos utilizados no } \\
\text { Centro Cirúrgico: pré e pós- } \\
\text { análise, ajustes e glosas }\end{array}$ \\
\hline & $\begin{array}{l}\text { Grupo cardíaco } \\
\text { pertencente }\end{array}$ & $\begin{array}{l}\text { Materiais utilizados no } \\
\text { Serviço de Hemodinâmica: pré } \\
\text { e pós-análise, ajustes, } \\
\text { divergências e glosas }\end{array}$ \\
\hline & $\begin{array}{c}\text { Data de chegada da conta } \\
\text { à USS }\end{array}$ & \multirow{6}{*}{$\begin{array}{l}\text { Medicamentos utilizados no } \\
\text { Serviço de Hemodinâmica: pré } \\
\text { e pós-análise, ajustes e glosas. }\end{array}$} \\
\hline & Tipo de conta & \\
\hline & $\begin{array}{l}\text { Cobrança: administrativa } \\
\text { (10 e quatro dias) e final }\end{array}$ & \\
\hline & $\begin{array}{l}\text { Período da alta do } \\
\text { paciente até a emissão da } \\
\text { conta à UFA }\end{array}$ & \\
\hline & $\begin{array}{c}\text { Tempo em que a conta } \\
\text { permanece na USS para } \\
\text { auditoria }\end{array}$ & \\
\hline & $\begin{array}{l}\text { Tempo total considerando } \\
\text { a auditoria e emissão da } \\
\text { conta pela UFA }\end{array}$ & \\
\hline Tipo de internação & $\begin{array}{l}\text { Data de fechamento da } \\
\text { conta pela UFA }\end{array}$ & \\
\hline
\end{tabular}

Fonte: Planilhas eletrônicas utilizadas pela equipe de auditoria da USS do InCor.

Após a realização da pré-análise pela equipe de auditoria, as contas são devolvidas à UFA com a indicação dos itens que necessitam de correção. Realizadas as correções a UFA encaminha as contas à USS para apresentação destas as operadoras de planos de saúde para auditoria (médica e de enfermagem) externa.

Ao final da negociação entre a USS e as operadoras de planos de saúde são identificadas as glosas. Então, as contas são enviadas a UFA para os ajustes finais permanecendo apenas os itens acordados entre os auditores internos e externos para emissão das notas fiscais e cobrança. 
Para ilustrar o processo de formação de conta hospitalar descrito apresentase o Fluxograma a seguir:

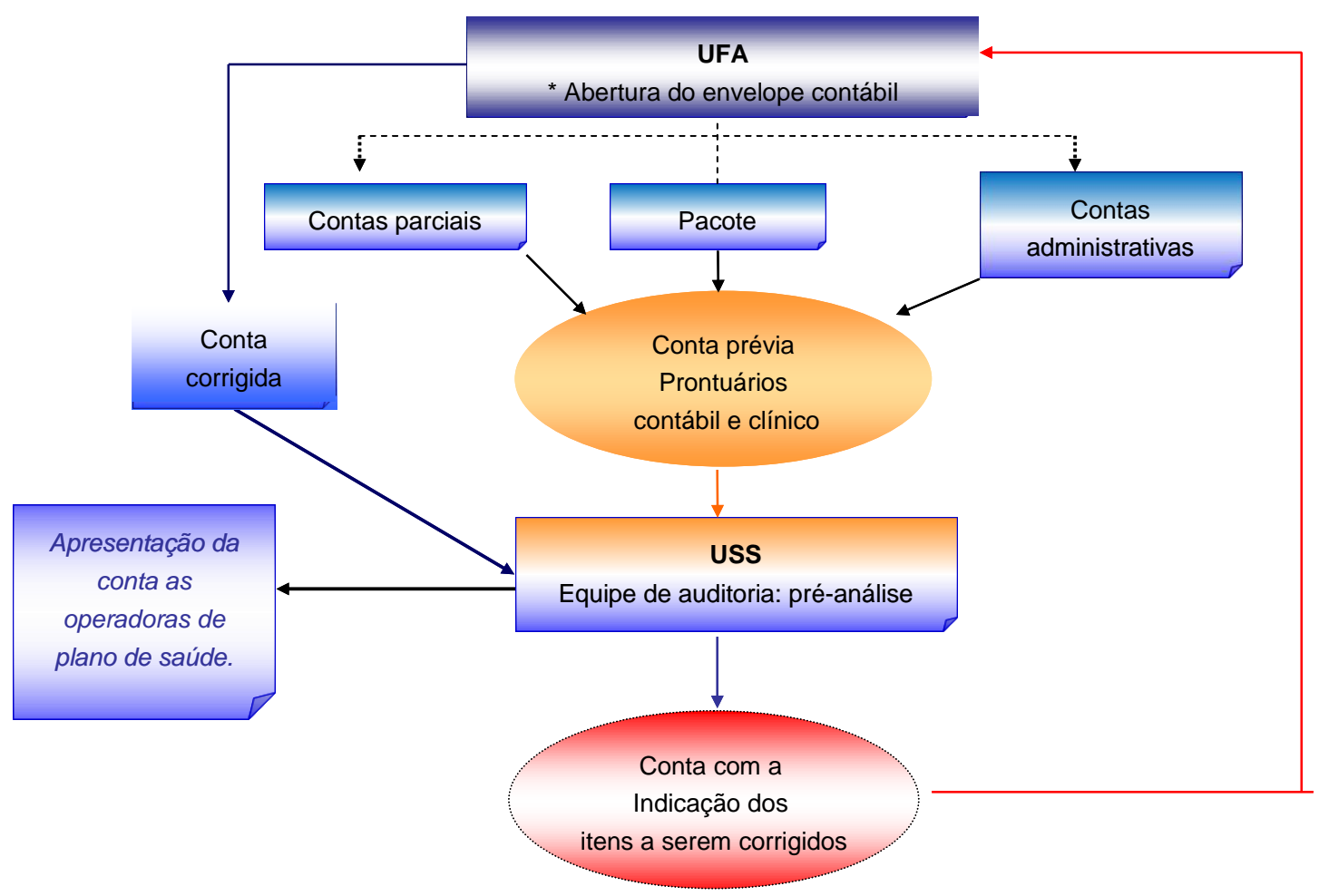

Figura 1- Fluxograma do processo de formação da conta hospitalar, São Paulo 2011.

\subsection{CRITÉRIOS DE INCLUSÃO}

- Contas hospitalares (administrativas e finais) com todos os itens preenchidos nas planilhas da equipe de auditoria.

\subsection{CRITÉRIOS DE EXCLUSÃO}

- Contas hospitalares (administrativas e finais) contendo itens incompletos nas planilhas da equipe de auditoria;

- Contas referentes às cobranças apenas por Pacote. 


\subsection{POPULAÇÃO}

Em 2011 foram enviadas à USS 3436 contas para auditoria. Destas, 823 foram excluídas por não contemplarem o critério de inclusão totalizando 2613 contas analisadas no presente estudo.

\subsection{COLETA DE DADOS}

3.6.1 Protocolo para realização do estudo de caso sobre auditoria de contas em um Hospital de Ensino Especializado em Cardiologia e Pneumologia

A fim de aumentar a confiabilidade do estudo de caso e direcionar o pesquisador na realização da coleta de dados ${ }^{42}$ utilizou-se o protocolo a seguir (Quadro 2), descrevendo as etapas da pesquisa, seus objetivos e as respectivas atividades: 
Quadro 2 - Protocolo para a realização do estudo de caso

\begin{tabular}{|c|c|}
\hline \multicolumn{2}{|c|}{ Etapa: PLANEJAMENTO } \\
\hline Objetivo & Atividade \\
\hline - Construir o protocolo & - Definir todas as etapas do protocolo \\
\hline \multicolumn{2}{|c|}{ Etapa: COLETA DE DADOS } \\
\hline Objetivo & Atividade \\
\hline $\begin{array}{l}\text { - Viabilizar a coleta dos dados } \\
\text { necessários à identificação da } \\
\text { percentagem do faturamento que os } \\
\text { auditores conseguem ajustar nas contas } \\
\text { hospitalares (administrativas e finais) }\end{array}$ & $\begin{array}{l}\text { - Obter a autorização da Diretoria da } \\
\text { USS para a utilização das planilhas } \\
\text { eletrônicas utilizadas pelos auditores no } \\
\text { ano de 2011; } \\
\text { - Elaborar planilha eletrônica, no } \\
\text { programa Microsoft Excel@, visando à } \\
\text { integração dos registros contidos nas } \\
\text { planilhas da equipe de auditoria; } \\
\text { - Agrupar e transportar os dados das } \\
\text { planilhas utilizadas pela equipe de } \\
\text { auditoria para a planilha eletrônica } \\
\text { integrada. }\end{array}$ \\
\hline \multicolumn{2}{|c|}{ Etapa: ANÁLISE DOS DADOS } \\
\hline Objetivo & Atividade \\
\hline $\begin{array}{l}\text { - Analisar os dados obtidos por meio da } \\
\text { planilha eletrônica integrada. }\end{array}$ & $\begin{array}{l}\text { - Providenciar tratamento estatístico dos } \\
\text { dados; } \\
\text { - Analisar descritivamente as variáveis } \\
\text { categóricas (frequências absolutas, as } \\
\text { frequências relativas, os intervalos de } \\
\text { confiança e moda); } \\
\text { - Analisar descritivamente as variáveis } \\
\text { contínuas (valor médio, desvio-padrão, } \\
\text { intervalos de confiança, mediana, moda, } \\
\text { valores mínimos e máximos; } \\
\text { - Demonstrar as variáveis categóricas } \\
\text { por meio de tabelas e gráficos; } \\
\text { - Discutir os dados na perspectiva da } \\
\text { auditoria hospitalar e do gerenciamento } \\
\text { de custos. }\end{array}$ \\
\hline \multicolumn{2}{|c|}{ Etapa: CONCLUSÃO } \\
\hline Objetivo & Atividades \\
\hline $\begin{array}{l}\text { - Apresentar as conclusões do } \\
\text { faturamento gerado pelos auditores ao } \\
\text { realizar a pré-análise das contas } \\
\text { hospitalares }\end{array}$ & $\begin{array}{l}\text { - Realizar a síntese dos resultados } \\
\text { obtidos. } \\
\text { - Recomendar melhorias no processo de } \\
\text { auditoria da USS a partir dos resultados } \\
\text { evidenciados. }\end{array}$ \\
\hline
\end{tabular}

Fonte: Adaptado de Yin $^{42}$ e Jericó ${ }^{43}$ 


\subsubsection{Procedimento para coleta de dados}

Para a coleta de dados obteve-se autorização junto a Diretoria da USS (Anexo I) para a utilização do banco de dados dos auditores que registram, diariamente, as contas e os valores nas planilhas eletrônicas acima mencionadas.

\subsubsection{Instrumento para coleta de dados}

Para a coleta de dados utilizou-se uma planilha eletrônica (Apêndice I) elaborada no programa Microsoft Exce ${ }^{\circledR}$, baseada nas planilhas utilizadas pelos auditores da USS do InCor, contendo:

Registro de internação do paciente;

Provedor (operadoras de planos de saúde e particular);

- Sexo;

- Idade;

- $\quad$ Tipo de internação (Clínica, Cirúrgica, de Hemodinâmica);

- Óbito;

- $\quad$ Diagnóstico Médico;

- Diárias hospitalares: apartamento, Unidade de Terapia Intensiva (UTI) e permanência total;

- Período inicial e final da conta;

- Valores iniciais, da pré-análise, ajustado e final;

- Valor da glosa total;

- Serviços de Enfermagem (valores referentes à: pré-análise, pós análise, ajuste e glosa);

- Equipamentos (valores referentes à: pré-análise, pós-análise, ajuste e glosa);

- $\quad$ Gases (valores referentes à: pré-análise, pós-análise, ajuste e glosa);

- Materiais de internação, Hemodinâmica e Centro Cirúrgico (valores referentes à: pré-análise, pós-análise, ajuste e glosa); 
- Medicamentos de internação Hemodinâmica e Centro Cirúrgico (valores referentes à: pré-análise, pós-análise, ajuste e glosa);

- $\quad$ Tempo em que o paciente recebeu alta até o preparo da primeira conta pela UFA;

- $\quad$ Tempo em que a conta fica na USS para pré-análise;

- Tempo de preparo da conta desde a alta e apresentação as fontes pagadoras.

- $\quad$ Tempo total da alta do paciente ao fechamento da conta pela UFA.

\subsubsection{Análise dos Dados}

$\mathrm{Na}$ análise descritiva das variáveis categóricas foram apresentadas as frequências absolutas, as frequências relativas e os intervalos de confiança (IC). Na análise descritiva das variáveis contínuas apresentou-se o valor médio, o desvio-padrão (DP), o IC, a mediana e os valores mínimos (min) e máximos (máx).

Testou-se a normalidade das variáveis por meio do teste de Kolmogorov-Smirnov ${ }^{44}$ e como todas apresentaram distribuição não normal foram utilizados apenas testes não-paramétricos.

Para comparar os valores médios de ajustes, tanto positivos como negativos, nas contas auditadas por enfermeiras, bem como os valores médios recebidos entre as quatro principais operadoras de saúde realizou-se o teste de Kruskall-Wallis ${ }^{44}$ e o post-hoc de Bonferroni ${ }^{44}$.

Para comparação do ajuste positivo total médio com o ajuste negativo total médio da equipe de auditoria realizou-se o teste de MannWhitney ${ }^{44}$. Empregou-se este teste também a fim de comparar os valores médios das glosas realizadas pelas enfermeiras com os valores médios das glosas realizadas pelos médicos.

Para comparar os valores médios recebidos entre os quatro principais convênios de saúde realizou-se o teste de Kruskall-Wallis e o posthoc de Bonferroni. 
Em todos os testes adotou-se o nível de 5\% de significância estatística. Todas as análises foram realizadas no pacote estatístico STATA 10.0 (Stata corp, Texas, USA) ${ }^{44}$.

A fim de retratar monetariamente os ajustes nas contas dos pacientes internados, no momento da pré-análise pela equipe de auditoria, bem como as glosas utilizou-se a moeda corrente no Brasil - Real (R\$).

\subsection{ASPECTOS ÉTICOS}

O projeto de pesquisa foi aprovado pelo Comitê de Ética em Pesquisa (CEP) da Escola de Enfermagem da Universidade de São Paulo (EEUSP), sob o parecer consubstanciado número: 12980 (Anexo II). 
No presente estudo foram analisadas 2.613 (100\%) contas, referentes ao período de janeiro a dezembro de 2011, enviadas a USS para realização da pré-análise pela equipe de auditoria, conforme indicado na Tabela 1:

Tabela 1 - Caracterização das contas hospitalares submetidas à pré-análise pela equipe de auditoria da USS - InCor HCFMUSP, São Paulo 2011.

\begin{tabular}{lccc}
\hline \multicolumn{1}{c}{ Variáveis } & N (2.613) & $\%$ & IC 95\% \\
\hline $\begin{array}{l}\text { Sexo } \\
\text { Masculino }\end{array}$ & 1.479 & 56,6 & 54,$7 ; 58,5$ \\
\hline Feminino & 1.134 & 43,4 & 41,$5 ; 45,3$ \\
\hline Idade & & & \\
\hline $1 \mid----15$ & 105 & 4,0 & 3,$2 ; 4,8$ \\
\hline $15 \mid---25$ & 19 & 0,7 & 0,$4 ; 1,0$ \\
\hline $25 \mid---60$ & 678 & 26,0 & 24,$3 ; 27,6$ \\
\hline $60|---| 100$ & 1.811 & 69,3 & 67,$5 ; 71,1$ \\
\hline Tipo de atendimento & & & \\
Particular & 218 & 8,3 & 7,$3 ; 9,4$ \\
\hline Operadoras de planos de saúde & 2.395 & 91,7 & 90,$6 ; 92,7$ \\
\hline Tipo de internação & & & \\
\hline Cirúrgica & 494 & 18,9 & 17,$4 ; 20,4$ \\
\hline Clinica & 1.393 & 53,3 & 51,$4 ; 55,4$ \\
\hline Hemodinâmica & 726 & 27,8 & 26,$1 ; 29,5$ \\
\hline Óbito & & & \\
$\quad$ Sim & 61 & 2,3 & 1,$7 ; 2,9$ \\
\hline Não & 2.552 & 97,7 & 97,$1 ; 98,2$ \\
\hline Especialidades médicas gerais e cardiológicas & & \\
Arritmia & 339 & 13,0 & 11,$7 ; 14,3$ \\
\hline Cardiologia Geral & 589 & 22,5 & 20,$9 ; 24,1$ \\
\hline Cardiopatias Congênitas & 85 & 3,3 & 2,$6 ; 3,9$ \\
\hline Cirurgia Geral & 77 & 3,0 & 2,$3 ; 3,6$ \\
\hline Coronária & 979 & 37,5 & 35,$6 ; 39,3$ \\
\hline Nefrologia & 7 & 0,3 & 0,$1 ; 0,5$ \\
\hline Pneumologia - Tórax & 218 & 8,3 & 7,$3 ; 9,4$ \\
\hline Transplante & 16 & 0,6 & 0,$3 ; 0,9$ \\
\hline Valvopatias & 187 & 7,2 & 6,$2 ; 8,1$ \\
\hline Vascular & 116 & 4,4 & 3,$7 ; 5,2$ \\
\hline
\end{tabular}


A Tabela 1 evidencia o predomínio de contas referentes à pacientes do sexo masculino $(56,6 \%)$, com idades que variaram de um a cem anos, média de 64,47 anos (DP \pm 19,18) e mediana de 67 de anos. Destes 2,3\% evoluíram a óbito.

A maioria $(91,7 \%)$ correspondeu à pacientes de operadoras de planos de saúde com contas clínicas (53,3\%).

Foram identificados 162 diagnósticos médicos (Apêndice II) e agrupados em 10 especialidades, gerais e cardiológicas, a partir da experiência clínica da pesquisadora com colaboração de um médico auditor da USS. Houve predomínio das especialidades cardiológicas sendo $37,5 \%$ referentes à Coronária e 22,54\% a Cardiologia Geral.

$\mathrm{Na}$ Tabela 2 são apresentadas as operadoras de planos de saúde conveniadas ao InCor HCFMUSP:

Tabela 2 - Distribuição das contas hospitalares por operadoras de planos de saúde submetidas à pré-análise pela equipe de auditoria da USS - InCor HCFMUSP, São Paulo - 2011.

\begin{tabular}{ccc}
\hline Operadoras de planos de saúde & Freqüência & $\%$ \\
\hline A & 661 & 27,6 \\
B & 418 & 17,45 \\
C & 243 & 10,15 \\
D & 165 & 6,89 \\
E & 116 & 4,84 \\
F & 107 & 4,47 \\
G & 91 & 3,80 \\
H & 71 & 2,96 \\
I & 68 & 2,84 \\
J & 67 & 2,80 \\
K & 61 & 2,55 \\
L & 42 & 1,75 \\
M & 34 & 1,42 \\
N & 32 & 1,34 \\
O & 32 & 1,34 \\
P & 20 & 0,84 \\
Q & 20 & 0,84 \\
R & 19 & 0,79 \\
\hline
\end{tabular}




\begin{tabular}{ccc}
\hline Operadoras de planos de saúde & Freqüência & $\%$ \\
\hline S & 18 & 0,75 \\
T & 17 & 0,71 \\
U & 17 & 0,71 \\
V & 13 & 0,54 \\
W & 13 & 0,54 \\
X & 13 & 0,54 \\
Y & 10 & 0,42 \\
Z & 6 & 0,25 \\
AA & 4 & 0,17 \\
AB & 3 & 0,13 \\
AC & 3 & 0,13 \\
AD & 3 & 0,13 \\
AE & 3 & 0,13 \\
AF & 2 & 0,08 \\
AG & 2 & 0,08 \\
AH & 1 & 0,04 \\
\hline TOTAL & $\mathbf{2 . 3 9 5}$ & $\mathbf{1 0 0}$ \\
\hline
\end{tabular}

Observa-se que dentre as 34 operadoras de planos de saúde conveniadas ao InCor HCFMUSP as quatro primeiras predominaram, correspondendo a $62,9 \%$ do faturamento total.

Em seguida são apresentados os valores médios do faturamento de 2011 relativos às operadoras $A, B, C$ e $D$ : 
Tabela 3 - Distribuição dos valores médios das contas hospitalares das operadoras de planos de saúde predominantes - InCor HCFMUSP, São Paulo - 2011.

\begin{tabular}{|c|c|c|c|c|c|}
\hline Variáveis & $\begin{array}{c}\text { Média } \\
\mathbf{R} \$\end{array}$ & $\begin{array}{c}\mathrm{DP} \pm \\
\mathrm{R} \$\end{array}$ & $\begin{array}{c}\text { IC } 95 \% \\
\text { R\$ }\end{array}$ & $\begin{array}{c}\text { Mediana } \\
\mathbf{R} \$\end{array}$ & $\begin{array}{c}\text { Min-Máx } \\
\text { R\$ }\end{array}$ \\
\hline \multicolumn{6}{|c|}{$\begin{array}{l}\text { Operadoras de } \\
\text { planos de saúde }\end{array}$} \\
\hline$A^{n=661}$ & $14.432,21$ & $15.833,37$ & $\begin{array}{c}13.222,95 \\
15.641,46\end{array}$ & $6.938,04$ & $\begin{array}{c}446,36- \\
106.851,60\end{array}$ \\
\hline $\mathrm{B}^{\mathrm{n}=418}$ & $11.753,21$ & $12.204,88$ & $\begin{array}{c}10.579,79 \\
12.926,64\end{array}$ & $7.051,12$ & $\begin{array}{c}117,00- \\
69.268,56\end{array}$ \\
\hline$C^{n=243}$ & $14.694,41$ & $15.906,61$ & $\begin{array}{c}12.684,39 \\
16.704,43\end{array}$ & $7.914,17$ & $\begin{array}{c}626,71- \\
80.438,67\end{array}$ \\
\hline$D^{n=165}$ & $19.187,50$ & $23.108,15$ & $\begin{array}{l}15.635,38 ; \\
22.739,62\end{array}$ & $9.820,50$ & $\begin{array}{c}824,30- \\
177.567,60\end{array}$ \\
\hline
\end{tabular}

Por meio da Tabela 3 constata-se que as operadoras de plano de saúde $D$ e $C$ apresentaram o maior valor médio dentre as predominantes variando de $R \$ 824,30$ a $R \$ 177.567,60$, com média de $R \$ 19.187,50$ (DP \pm $23.108,15)$ e mediana de $R \$ 9.820,50$ na primeira e com variação de $R \$$ 626,71 a $R \$ 80.438,67$, com média de $R \$ 14.694,41$ (DP $\pm 15.906,61$ ) e mediana de $R \$ 7.914,17$ na segunda.

Tabela 4 - Distribuição das diárias nas contas hospitalares auditadas - InCor HCFMUSP, São Paulo - 2011.

\begin{tabular}{lccccc}
\hline Variáveis & Média & DP \pm & IC 95\% & Mediana & Min-Máx \\
\hline Diárias (dias) $^{\text {Apartamento }}{ }^{\mathrm{n}=2.332}$ & & & & & \\
UTI $^{\mathrm{n}=939}$ & 4,26 & 3,14 & 4,$1 ; 4,4$ & 3 & $1-13$ \\
Permanência $^{\mathrm{n}=2.613}$ & 4,48 & 3,12 & 4,$3 ; 4,7$ & 4 & $1-12$ \\
\hline
\end{tabular}


Na Tabela 4 verifica-se que os dias de internação em apartamento variaram de 1 a 13, com média de 4,26 (DP $\pm 3,14)$ e mediana de 3 dias; os dias de internação em UTI de 1 a 12, com média de 4,48 (DP \pm 3,12) e mediana de 4 dias, perfazendo um total médio de 5,41 dias de permanência.

Tabela 5 - Distribuição da inclusão dos Itens componentes das contas hospitalares auditados por enfermeiras da USS - InCor HCFMUSP, São Paulo - 2011.

\begin{tabular}{|c|c|c|c|c|c|}
\hline Variáveis & $\begin{array}{c}\text { Média } \\
\text { R\$ }\end{array}$ & $\begin{array}{c}\mathrm{DP} \pm \\
\mathrm{R} \$\end{array}$ & $\begin{array}{c}\text { IC } 95 \% \\
\mathrm{R} \$\end{array}$ & $\begin{array}{c}\text { Mediana } \\
\quad \mathbf{R} \$ \\
\end{array}$ & $\begin{array}{c}\text { Min-Máx } \\
\text { R\$ }\end{array}$ \\
\hline \multicolumn{6}{|l|}{ Auditorias } \\
\hline $\begin{array}{l}\text { Serviços de } \\
\text { enfermagem }^{\mathrm{n}=2.175}\end{array}$ & 275,63 & 491,66 & $\begin{array}{l}249,8 \\
301,4\end{array}$ & 104,54 & $\begin{array}{c}0,02- \\
8.399,4\end{array}$ \\
\hline Equipamentos $^{\mathrm{n}=1.888}$ & 689,42 & $1.145,2$ & $\begin{array}{l}619,5 \\
759,4\end{array}$ & 247,91 & $\begin{array}{c}0,39- \\
10.173,8\end{array}$ \\
\hline Gases $^{n=2.365}$ & 707,91 & 843,95 & $\begin{array}{l}657,5 \\
778,3\end{array}$ & 403,20 & $\begin{array}{c}0,06- \\
11.565,5\end{array}$ \\
\hline $\begin{array}{l}\text { Materiais de } \\
\text { internação }{ }^{n=2.218}\end{array}$ & 224,68 & $1.307,61$ & $\begin{array}{l}163,4 \\
285,9\end{array}$ & 63,43 & $\begin{array}{c}0,03- \\
51.964,9\end{array}$ \\
\hline $\begin{array}{l}\text { Medicamentos de } \\
\text { internação }^{n=1.536}\end{array}$ & 286,88 & 777,84 & $\begin{array}{c}238,8 \\
334,9\end{array}$ & 90,72 & $\begin{array}{c}0,01- \\
13.882,6\end{array}$ \\
\hline $\begin{array}{l}\text { Materiais de Centro } \\
\text { Cirúrgico }^{n=231}\end{array}$ & 404,57 & $1.080,65$ & $\begin{array}{l}227,8 \\
581,3\end{array}$ & 121,36 & $\begin{array}{c}0,12- \\
10.560,6\end{array}$ \\
\hline $\begin{array}{l}\text { Medicamentos de } \\
\text { Centro cirúrgico }^{n=323}\end{array}$ & 383,74 & 520,04 & $\begin{array}{l}301,8 \\
465,7\end{array}$ & 297,12 & $\begin{array}{c}0,30- \\
4.634,2\end{array}$ \\
\hline $\begin{array}{l}\text { Materiais de } \\
\text { Hemodinâmica }^{\mathrm{n}=786}\end{array}$ & $1.055,90$ & $3.953,45$ & $\begin{array}{c}6,91 ; \\
2.194,8\end{array}$ & 51 & $\begin{array}{c}0,82- \\
26.557,3\end{array}$ \\
\hline $\begin{array}{l}\text { Medicamento } \\
\text { Hemodinâmican=768 }\end{array}$ & 524,64 & 463,50 & $\begin{array}{l}427,0 \\
622,3\end{array}$ & 370,17 & $\begin{array}{c}4,0- \\
1.900,0\end{array}$ \\
\hline
\end{tabular}

De acordo com a Tabela 5 os itens componentes das contas hospitalares analisados por enfermeiros que mais receberam ajustes positivos (inclusões), no momento da pré-análise, foram gases $(90,5 \%)$; materiais de internação (85\%) e serviço de enfermagem $(83,2 \%)$. 
Os itens que contribuíram para maior impacto financeiro nos ajustes positivos foram os materiais de Hemodinâmica, com variação de $R \$$ 0,82 a $R \$ 26.557,30$, média de $R \$ 1.055,90(D P \pm 3.953,45)$ e mediana de $R \$ 51,00$; gases variando entre $R \$ 0,06$ a $R \$ 11.565,50$, com média de $R \$$ 707, 91 (DP \pm 843,95) e mediana de $\mathrm{R} \$ 403,20$ e equipamentos com variação de $R \$ 0,39$ a $R \$ 10.173,80$, com média de $R \$ 689,42$ (DP \pm $1145,20)$ e mediana de $\mathrm{R} \$ 247,91$.

Tabela 6 - Distribuição da exclusão dos Itens componentes das contas hospitalares auditados por enfermeiras da USS - InCor HCFMUSP, São Paulo - 2011.

\begin{tabular}{|c|c|c|c|c|c|}
\hline Variáveis & $\begin{array}{l}\text { Média } \\
\text { R\$ }\end{array}$ & $\begin{array}{l}\mathrm{DP} \pm \\
\mathrm{R} \$\end{array}$ & $\begin{array}{c}\text { IC } 95 \% \\
\text { R\$ }\end{array}$ & $\begin{array}{c}\text { Mediana } \\
\quad \mathbf{R} \$\end{array}$ & $\begin{array}{c}\text { Min-Máx } \\
\text { R\$ }\end{array}$ \\
\hline \multicolumn{6}{|l|}{ Auditorias } \\
\hline $\begin{array}{l}\text { Serviços de } \\
\text { enfermagem }^{n=438}\end{array}$ & 130,02 & 246,02 & $\begin{array}{l}106,9 \\
153,1\end{array}$ & 40,9 & $\begin{array}{c}0,03- \\
2.462,8\end{array}$ \\
\hline Equipamentos $^{\mathrm{n}=725}$ & 656,18 & 2075,04 & $\begin{array}{l}504,8 \\
807,4\end{array}$ & 190,8 & $\begin{array}{c}0,3- \\
45.460,7\end{array}$ \\
\hline Gases $^{n=248}$ & $1.048,51$ & 3025,53 & $\begin{array}{c}670,1 ; \\
1.426,9\end{array}$ & 244,1 & $\begin{array}{c}3,08- \\
25.562,9\end{array}$ \\
\hline $\begin{array}{l}\text { Materiais de } \\
\text { internação }{ }^{n=395}\end{array}$ & 293,06 & 785,58 & $\begin{array}{l}215,3 \\
370,7\end{array}$ & 56,1 & $\begin{array}{c}0,08- \\
10.201,7\end{array}$ \\
\hline $\begin{array}{l}\text { Medicamentos de } \\
\text { internação }\end{array}$ & 547,97 & 1302,49 & $\begin{array}{l}470,1 \\
625,8\end{array}$ & 183,9 & $\begin{array}{c}0,09- \\
1.8154,3\end{array}$ \\
\hline $\begin{array}{l}\text { Materiais de Centro } \\
\text { Cirúrgico }^{n=277}\end{array}$ & 147,41 & 480,54 & $\begin{array}{l}90,5 \\
204,2\end{array}$ & 33,9 & $\begin{array}{c}0,39- \\
5.838,2\end{array}$ \\
\hline $\begin{array}{l}\text { Medicamentos de } \\
\text { Centro cirúrgico }=181\end{array}$ & 365,88 & 460,35 & $\begin{array}{l}298,3 \\
433,4\end{array}$ & 198,04 & $\begin{array}{c}0,03- \\
2.815,42\end{array}$ \\
\hline $\begin{array}{l}\text { Materiais } \\
\text { Hemodinâmica }{ }^{\mathrm{n}=39}\end{array}$ & $3.860,15$ & $15.220,80$ & $\begin{array}{c}-1.073,8 \\
8.794,1\end{array}$ & 89,1 & $\begin{array}{c}0,12- \\
94.206,5\end{array}$ \\
\hline $\begin{array}{l}\text { Medicamentos } \\
\text { Hemodinâmica }^{\mathrm{n}=35}\end{array}$ & $1.983,04$ & 8324,42 & $\begin{array}{l}-876,4 \\
4842,5\end{array}$ & 419,0 & $\begin{array}{c}0,03- \\
49.704,0\end{array}$ \\
\hline
\end{tabular}


A partir dos dados obtidos na Tabela 6 constata-se que os itens componentes das contas hospitalares examinados por enfermeiros que mais receberam ajustes negativos (exclusões), no momento da pré-análise, foram medicamentos de internação (41,2\%); equipamentos $(28 \%)$ e serviços de enfermagem (17\%).

Em relação ao maior impacto financeiro nos ajustes negativos os itens que mais contribuíram foram os materiais de Hemodinâmica, com variação de $R \$ 0,12$ a $R \$ 94.206,50$, média de $R \$ 3.860,15(D P \pm 15.220,80)$ e mediana de $R \$ 89,10$ seguidos por medicamentos utilizados na Hemodinâmica variando entre $R \$ 0,03$ a $R \$ 49.704$, 00, com média de $R \$$ $1.983,04(\mathrm{DP} \pm 8.324,42)$ e mediana de $\mathrm{R} \$ 419,00$ e gases com variação de $R \$ 3,08$ a $R \$ 25.562,90$, com média de $R \$ 1.048,51$ (DP $\pm 3.025,53$ ) e mediana de $R \$ 244,10$.

Apresenta-se a seguir, nos Gráficos 1 e 2, o impacto dos ajustes positivos e negativos no faturamento das contas hospitalares auditadas no período estudado:

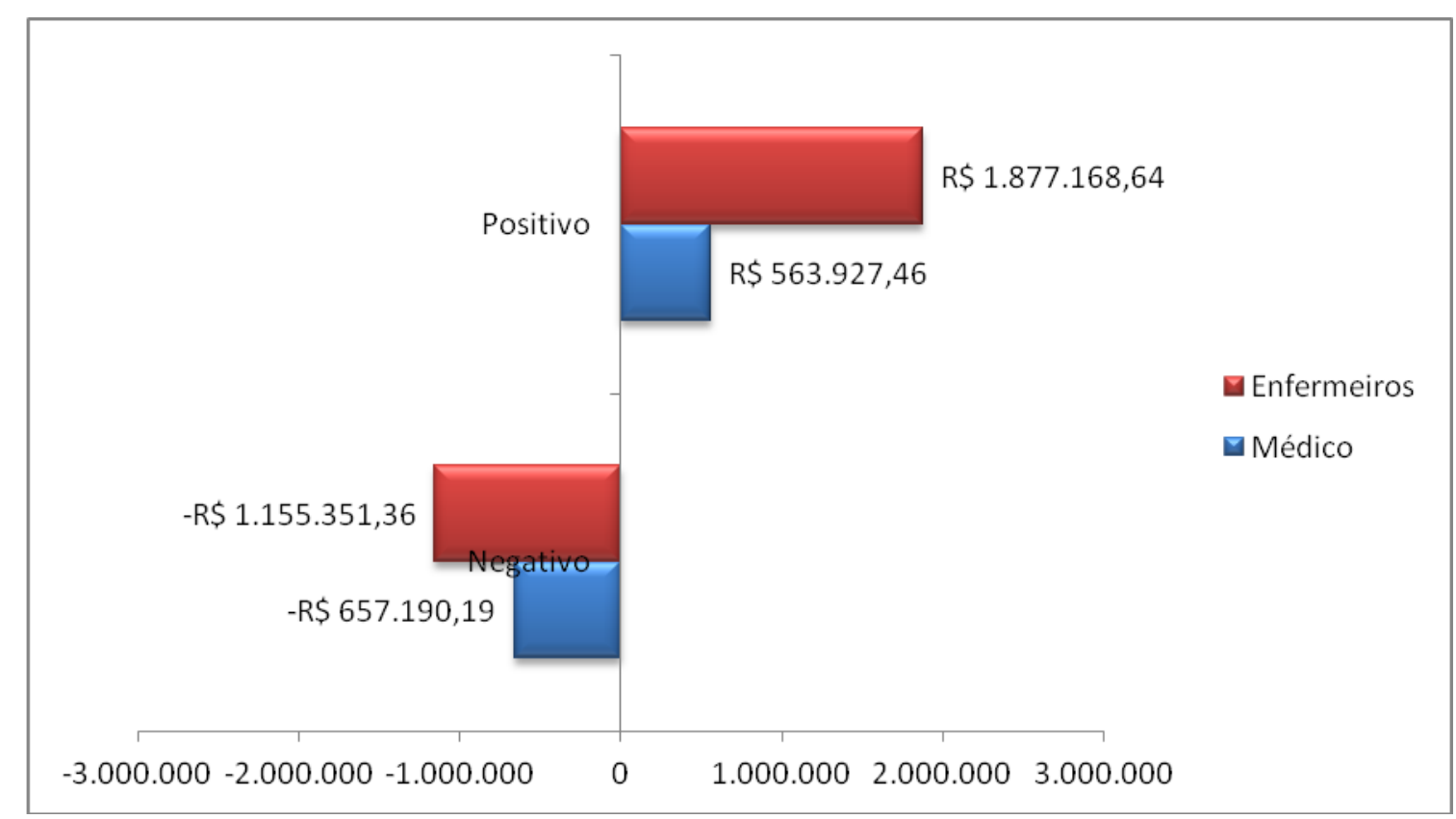

Gráfico 1 - Faturamento relativo aos ajustes positivo e negativo realizados nas contas hospitalares pela equipe de auditoria da USS - InCor HCFMUSP, São Paulo - 2011. 
O Gráfico 1 demonstra o impacto dos ajustes positivos (inclusões) e negativos (exclusões) realizados pela equipe de auditoria. $O$ faturamento das enfermeiras auditoras correspondeu à inclusão de $R$ \$ 1.877.168,64 e exclusão de $R \$ 1.155 .351,36$ e dos médicos auditores a inclusão de $R \$$ $563.927,46$ e exclusão de $R \$ 657.190,19$.

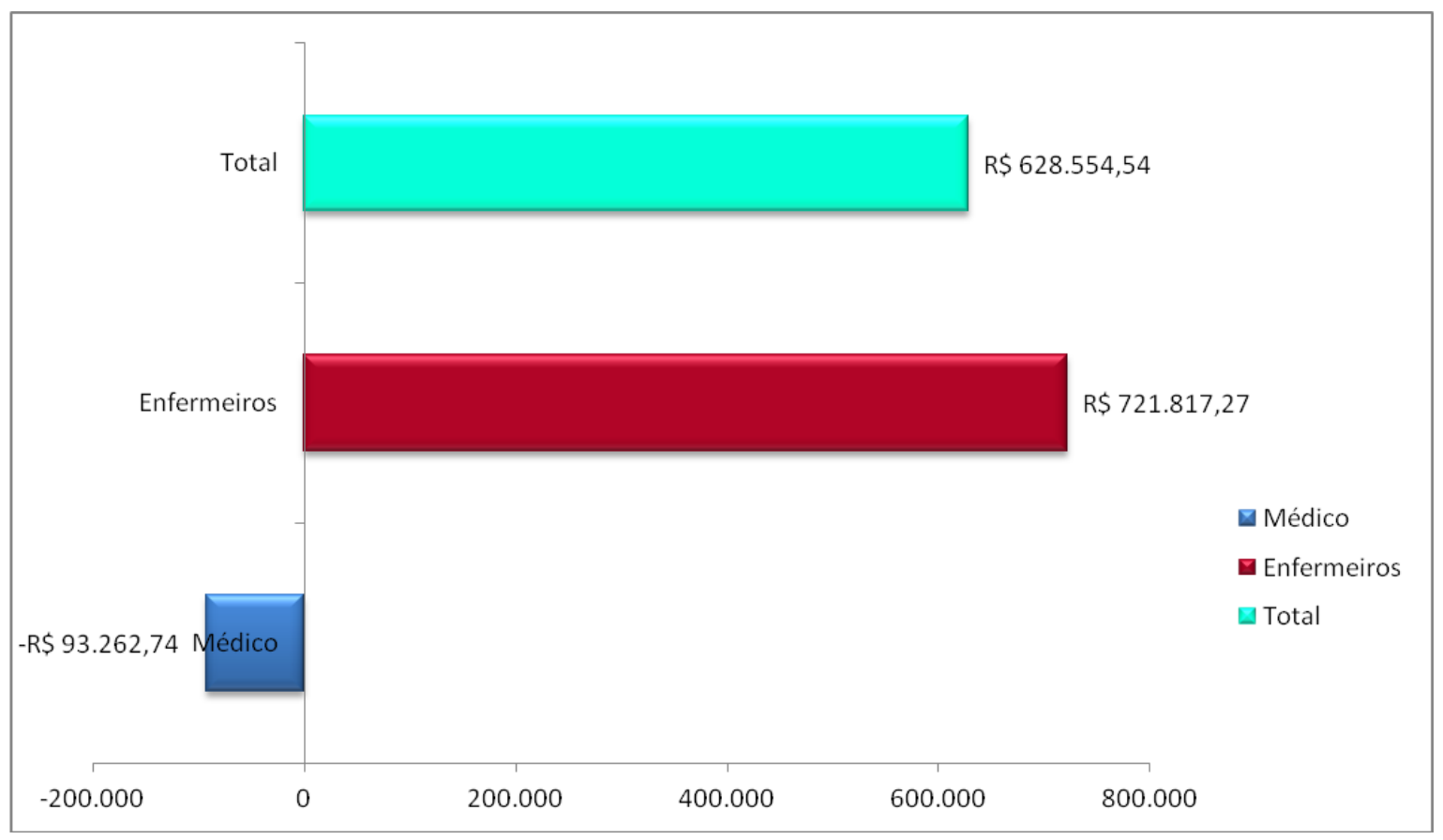

Gráfico 2 -Faturamento total relativo aos ajustes positivo e negativo realizados nas contas hospitalares pela equipe de auditoria da USS - InCor HCFMUSP, São Paulo - 2011.

No Gráfico 2 evidencia-se que, no faturamento total referente ao ano de 2011, as enfermeiras auditoras foram responsáveis pelo ajuste positivo de $\mathrm{R} \$ 721.817,28$ (115\%) e os médicos auditores pelo ajuste negativo de $\mathrm{R} \$ 93.262,73$.

A Tabela 7 mostra o faturamento ajustado pela equipe de auditoria nas contas hospitalares referentes ao período do estudo: 
Tabela 7 - Distribuição média dos ajustes realizados nas contas hospitalares pela equipe de auditoria da USS - InCor HCFMUSP, São Paulo 2011.

\begin{tabular}{|c|c|c|c|c|c|}
\hline Variáveis & $\begin{array}{c}\text { Média } \\
\mathbf{R} \$\end{array}$ & $\begin{array}{c}\mathrm{DP} \pm \\
\mathrm{R} \$\end{array}$ & $\begin{array}{c}\text { IC } 95 \% \\
\text { R\$ }\end{array}$ & $\begin{array}{c}\text { Mediana } \\
\text { R\$ }\end{array}$ & $\begin{array}{c}\text { Min-Máx } \\
\text { R\$ }\end{array}$ \\
\hline \multicolumn{6}{|l|}{ Ajustes } \\
\hline $\begin{array}{l}\text { Ajuste } \\
\text { positivo total }{ }^{\mathrm{n}=1.505}\end{array}$ & $1.340,75$ & $2.502,93$ & $\begin{array}{l}1.214,2 \\
1.467,3\end{array}$ & 440,00 & $\begin{array}{c}0,40- \\
30.024,60\end{array}$ \\
\hline $\begin{array}{l}\text { Ajuste } \\
\text { negativo total }^{\mathrm{n}=884}\end{array}$ & $1.571,58$ & $5.990,51$ & $\begin{array}{l}1.176,1 \\
1.967,0\end{array}$ & 329,17 & $\begin{array}{c}0,47- \\
133.906,0\end{array}$ \\
\hline
\end{tabular}

Conforme a Tabela acima, 2.389 (91,42\%) contas hospitalares receberam ajustes sendo $57,59 \%$ positivos e $33,83 \%$ negativos. Houve variação do ajuste positivo total de $R \$ 0,40$ a $R \$ 30.024,60$; com média de $\mathrm{R} \$ 1.340,75(\mathrm{DP} \pm 2.502,93)$; mediana de $\mathrm{R} \$ 440,00$. O ajuste negativo total variou entre $R \$ 0,47$ e $R \$ 133.906,00$; com média de $R \$ 1.571,58$ (DP士 $5.990,51)$ e mediana de $\mathrm{R} \$ 329,17$.

Identificam-se na Tabela 8 as glosas relativas aos itens conferidos pela equipe de auditoria:

Tabela 8 - Distribuição média das glosas recebidas pela equipe de auditoria da USS - InCor HCFMUSP, São Paulo - 2011.

\begin{tabular}{lccccc}
\hline \multicolumn{1}{c}{ Variáveis } & Média & $\mathrm{DP} \pm$ & IC 95\% & Mediana & Min-Máx \\
& $\mathrm{R} \$$ & $\mathrm{R} \$$ & $\mathrm{R} \$$ & $\mathrm{R} \$$ & $\mathrm{R} \$$ \\
\hline Glosa & & & & & \\
\hline Médicas $^{\mathrm{n}=807}$ & \multirow{2}{*}{311,94} & 646,86 & 267,$2 ;$ & 173,50 & $0,02-12.832,80$ \\
& & & 356,6 & & \\
Enfermagem $^{\mathrm{n}=1.076}$ & 255,84 & \multirow{2}{*}{$1.636,76$} & 157,$9 ;$ & 29,44 & $0,36-44.418,00$ \\
& & & 353,8 & & \\
\hline Mann-Whitney $\mathrm{p}<0,01$ & & & & &
\end{tabular}


De acordo com a Tabela 8 houve variação das glosas médicas de $R \$ 0,02$ a $R \$ 12.832,80$, média de $R \$ 311,94$ ( $D P \pm 646,86)$; mediana de $R \$$ 173,50 e as glosas de enfermagem variaram entre $R \$ 0,36$ e $R \$ 44.418,00$, com média de $\mathrm{R} \$ 255,84(\mathrm{DP} \pm 1.636,76)$ e mediana de $\mathrm{R} \$ 29,44$.

Considerando-se que ocorreram glosas em itens analisados por enfermeiras ou por médicos, bem como em itens examinados por ambos, 0 total de glosas correspondeu a $R \$ 380,51$ em média $(D P \pm 1.533,05)$, com mediana de $\mathrm{R} \$ 117,07$.

Os itens glosados das contas hospitalares conferidos pelas enfermeiras auditoras estão discriminados na Tabela 9:

Tabela 9 - Distribuição das glosas dos itens componentes das contas hospitalares, auditados por enfermeiras. InCor HCFMUSP, São Paulo - 2011.

\begin{tabular}{|c|c|c|c|c|c|}
\hline Variáveis & $\begin{array}{c}\text { Média } \\
\mathrm{R} \$\end{array}$ & $\begin{array}{l}\text { DP } \\
R \$\end{array}$ & $\begin{array}{c}\text { IC } 95 \% \\
\text { R\$ }\end{array}$ & $\begin{array}{c}\text { Mediana } \\
\text { R\$ }\end{array}$ & $\begin{array}{c}\text { Min-Máx } \\
\text { R\$ }\end{array}$ \\
\hline $\begin{array}{l}\text { Serviços de } \\
\text { enfermagem }\end{array}$ & 50,23 & 112,65 & $\begin{array}{l}30,9 \\
69,6\end{array}$ & 17,72 & $1,00-863,0$ \\
\hline Equipamentos $^{\mathrm{n}=98}$ & 392,75 & $1.019,36$ & $\begin{array}{l}188,4 \\
597,1\end{array}$ & 83,30 & $1,50-8.331,9$ \\
\hline Gases $^{n=65}$ & 292,33 & 523,70 & $\begin{array}{l}162,6 \\
422,1\end{array}$ & 84,48 & $5,70-3 \cdot 329,5$ \\
\hline $\begin{array}{l}\text { Materiais de } \\
\text { internação }^{n=541}\end{array}$ & 42,52 & 192,95 & $\begin{array}{l}26,2 \\
58,8\end{array}$ & 9,60 & $0,20-3.864,0$ \\
\hline $\begin{array}{l}\text { Medicamentos de } \\
\text { internaçãon }^{n=336}\end{array}$ & 238,62 & $2.450,30$ & $\begin{array}{l}-24,3 \\
501,6\end{array}$ & 24,54 & $0,40-44.418,0$ \\
\hline $\begin{array}{l}\text { Materiais de Centro } \\
\text { Cirúrgico }\end{array}$ & 47,25 & 132,67 & $\begin{array}{l}29,8 \\
64,7\end{array}$ & 11,46 & $0,40-1.561,2$ \\
\hline $\begin{array}{l}\text { Medicamentos de } \\
\text { Centro Cirúrgico }^{n=87}\end{array}$ & 200,28 & 377,43 & $\begin{array}{l}119,8 \\
280,7\end{array}$ & 58,98 & $0,50-2.468,3$ \\
\hline $\begin{array}{l}\text { Materiais de } \\
\text { Hemodinâmica }^{\mathrm{n}=250}\end{array}$ & 30,96 & 369,22 & $\begin{array}{c}-15,0 \\
77,0\end{array}$ & 2,73 & $0,40-5.825,0$ \\
\hline $\begin{array}{l}\text { Medicamentos } \\
\text { Hemodinâmica }^{\mathrm{n}=17}\end{array}$ & 47,54 & 58,27 & $\begin{array}{l}17,6 \\
77,5\end{array}$ & 17,17 & $1,20-187,5$ \\
\hline
\end{tabular}


A Tabela 9 mostra que os itens mais receberam glosas na auditoria de enfermagem foram os materiais de internação, medicamentos de internação e materiais de Hemodinâmica.

Os itens que contribuíram para maior impacto financeiro nas glosas foram os equipamentos com variação de $R \$ 1,50$ a $R \$ 8.331,90$, média de $R \$ 392,75(\mathrm{DP} \pm 1019,36)$ e mediana de $\mathrm{R} \$$ 83,30; gases variando entre $R \$ 5,70$ a $R \$ 3.329$, 50, com média de $R \$ 292,33$ (DP \pm 523,70), mediana de $R \$ 84,48$ e medicamentos de internação com variação de $R \$$ 0,40 a $R \$ 44.418,00$, com média de $R \$ 238,62(D P \pm 2.450,30)$ e mediana de $\mathrm{R} \$ 24,54$.

Nas contas auditadas por médicos não foi possível discriminar os itens glosados e com maior impacto financeiro devido à ausência deste registro na planilha eletrônica específica por eles utilizada.

Por fim demonstram-se na Tabela 10 os dias de permanência da conta hospitalar, em cada Unidade, durante o processo de formação:

Tabela 10 - Distribuição dos dias de permanência da conta hospitalar na UFA e USS do InCor HCFMUSP até a sua apresentação às fontes pagadoras, São Paulo- 2012.

\begin{tabular}{lccccc}
\hline \multicolumn{1}{c}{ Variáveis } & Média & DP & IC 95\% & Mediana & Min-Máx \\
\hline UFA & 23,08 & 27,94 & $\begin{array}{r}22,0 ; \\
24,2\end{array}$ & 16 & $0-703$ \\
USS & 6,96 & 8,58 & $\begin{array}{c}6,6 ; \\
7,3\end{array}$ & 5 & $0-166$ \\
UFA + USS & 30,03 & 30,63 & $\begin{array}{c}28,9 ; \\
31,2\end{array}$ & 22 & $1-707$ \\
& & & & \\
Tempo total & 33,92 & 31,72 & 32,$7 ;$ \\
& & & 35,1 & & $0-713$ \\
\hline
\end{tabular}

O tempo total de formação da conta hospitalar no InCor variou de 0 a 713 dias, com média de 33,92 (DP \pm 31,72) e mediana de 26 dias. Percebe-se que o maior tempo de permanência ocorreu na UFA com variação de 0 a 703, média de 23,08 (DP \pm 27,94) e mediana de 16 dias. 
Os resultados obtidos demonstram o predomínio das contas de pacientes do sexo masculino, com idade média de 64 anos. Estima-se que em 2020, a maioria dos óbitos nos países em desenvolvimento será relacionada ao envelhecimento populacional devido às doenças crônicas, em especial às doenças do sistema circulatório ${ }^{45}$.

No SUS o coeficiente de hospitalização (número de hospitalizações dividido pelo número de habitantes), 0 índice de hospitalização (número de dias de hospitalização consumido por habitante e ano) e o índice de custo de hospitalizações (custo de hospitalização consumido por habitante) são mais altos para a faixa de 60+ anos do que para qualquer outra faixa etária da população brasileira. Após os 60 anos de idade o índice de hospitalização e o índice de custo hospitalar aumentam progressivamente e a ocorrência de reinternações entre os idosos é cinco vezes maior do que na faixa etária de 15-59 anos ${ }^{46}$. Acredita-se que esta realidade também seja condizente aos pacientes atendidos na SS, por meio das operadoras de planos de saúde e convênios.

Dos diagnósticos contidos nas contas hospitalares, houve a prevalência da especialidade Coronariana, conforme o esperado devido à especificidade Institucional. Destaca-se que a Doença Arterial Coronariana (DAC) é uma das principais causas de morte sendo a primeira na população de 60 anos ou mais. A sua incidência está aumentando em países em desenvolvimento, em parte pelo aumento da longevidade, urbanização e mudanças de hábitos diários ${ }^{45}$.

A DAC é considerada a causa mais importante de morte e incapacitação entre os homens e entre as mulheres após os 40 anos de idade. O prognóstico para as mulheres é pior, pois o risco de morte nas primeiras semanas e no primeiro ano após o evento é duas vezes maior ${ }^{47}$.

De acordo com estudo desenvolvido em 2001 sobre o custo das internações hospitalares entre idosos no SUS as doenças do aparelho circulatório e respiratório corresponderam cerca de metade dos custos obtidos. As internações por doenças isquêmicas do coração representaram a quinta causa $(4,0 \%)$ e foram responsáveis pelo maior custo $(13 \%)$ entre todas as causas de internações ${ }^{48}$. 
Ribeiro et $a^{49}$ identificaram 0 custo anual do manejo da cardiopatia isquêmica crônica no Brasil sob a perspectiva pública e privada. Constataram que a média do custo por paciente da SS foi de $R \$ 6.788,00$ e os gastos hospitalares corresponderam a $69 \%$ deste valor. Pelo SUS o custo anual foi de $\mathrm{R} \$ 2.733,00$ sendo o manejo ambulatorial responsável por $54 \%$ deste total e os gastos com o tratamento farmacológico representou $77,5 \%$ dos custos ambulatoriais e $42 \%$ do total ${ }^{49}$.

No presente estudo observa-se prevalência de contas provenientes das operadoras de planos de saúde em relação às particulares. Em 2006 cerca de 19,8\% da população brasileira possuía planos de assistência médica, distribuídos de maneira desigual entre as regiões do país, com maior expressão nas áreas urbanas e nos estados com maior renda e oferta de emprego: Vitória $(67,6 \%)$, São Paulo $(59,2 \%)$, Rio de janeiro $(49,0 \%)^{50}$.

O faturamento gerado por operadoras de planos de saúde no InCor concentrou-se em 04 (62,9\%) dentre as 34 credenciadas. Resultados semelhantes foram encontrados nos estudos de Zunta ${ }^{25}$ (3 operadoras $50,3 \%$ ) e Teixeira $^{51}$ (3 operadoras - 51,4\%).

Houve a predominância da operadora $A(27,6 \%)$, contudo o maior valor médio obtido por conta referiu-se a operadora $D$ com $R \$ 19.187,50$. Destaca-se que apesar de alguns preços serem iguais, pode haver diferenças de faturamento decorrentes dos acordos comerciais e contratuais realizados entre os prestadores e os compradores de serviços de saúde.

Esta concentração do faturamento poderia ter gerado dependência financeira e comprometimento da receita caso não tivesse ocorrido o pagamento devido. Assim, concorda-se com Teixeira ${ }^{51}$ sobre a necessidade de divisão do faturamento hospitalar entre várias operadoras, denominada pulverização, para que a instituição não se torne dependente financeiramente de um número limitado de operadoras.

Gases (90,5\%); materiais de internação (85\%) e serviço de enfermagem $(83,2 \%)$ foram os itens das contas hospitalares analisados por enfermeiros que mais receberam ajustes positivos (inclusões). No entanto, 
os itens que apresentaram maior impacto financeiro nas inclusões foram os materiais de Hemodinâmica; gases e equipamentos.

O paciente portador de cardiopatia e pneumopatia pode necessitar de oxigênio, ar comprimido, óxido nítrico prescritos separadamente ou de maneira combinada de acordo com as indicações clínico-terapêuticas, sendo seu consumo registrado pela equipe de enfermagem, no prontuário clínico.

Nas contas estudadas observa-se a constante inclusão de materiais de internação. O consumo destes materiais deveria ser registrado em nota de débito pela enfermeira ou auxiliar de enfermagem, mas a documentação não ocorre de forma adequada. Um motivo possível para que isso ocorra é o fato da maioria dos pacientes do InCor ser proveniente do SUS, não necessitando da documentação rigorosa dos materiais a fim de comprovar o uso com a finalidade de subsidiar o recebimento do pagamento.

Assim, destaca-se como relevante, a educação permanente e contínua conscientização dos profissionais em relação à utilização correta dos materiais de consumo, bem como a realização de programas de treinamentos para incrementar a documentação da assistência prestada independentemente, do tipo de fonte pagadora.

Os serviços de enfermagem lançados na conta do paciente são registrados na nota débito a partir da prescrição e anotação de enfermagem. Porém, a exemplo do que acontece em outras realidades, se observa um sub-registro das ações desenvolvidas, por vezes devido à sobrecarga de trabalho que compromete a documentação logo após a realização de um procedimento/atendimento.

Ainda são escassos os estudos que abordem a relação entre a adequada documentação de enfermagem e o faturamento hospitalar. Estudo realizado por Zunta, Castilho ${ }^{25}$ evidenciou que os profissionais de enfermagem foram responsáveis por $15,1 \%$ do faturamento total, sendo $11,3 \%$ proveniente da prescrição de enfermagem. Já no trabalho de Teixeira $^{51}$ a equipe de enfermagem foi responsável por 1,7\% do faturamento em UTI, diferença atribuída às baixas taxas negociadas entre o hospital e as operadoras de planos de saúde. 
Salienta-se que o conhecimento sobre os custos dos materiais, equipamentos e procedimentos realizados é imprescindível à equipe de enfermagem podendo contribuir para melhorar os registros da assistência prestada e diminuir as perdas de faturamento e glosas hospitalares ${ }^{37}$.

Nos ajustes positivos os materiais de hemodinâmica foram os itens de maior impacto financeiro por seu alto valor. Cardoso ${ }^{52}$ afirma que o serviço de Cardiologia Intervencionista, em virtude dos avanços tecnológicos, possui alto custo em decorrência da necessidade de renovação freqüente, representando cerca de $75 \%$ dos custos diretos de um Setor de Hemodinâmica.

Os pacientes internados no InCor, geralmente, necessitam de bomba de infusão, monitor cardíaco, oxímetro, telemetria, entre outros equipamentos disponíveis, que demandariam a devida documentação na prescrição e anotações de enfermagem, o que frequentemente também não aconteceu. As taxas de uso desses equipamentos correspondem ao valor cobrado pela sua utilização e depreciação. A cobrança é feita de acordo com os diferentes contratos estabelecidos: por hora de uso; por dia ou por períodos, como até quatro horas, não necessitando constar em prescrição médica. Portanto, se evidencia, novamente, a importância da documentação de enfermagem para o faturamento hospitalar.

Os itens que mais receberam ajustes negativos (exclusões) foram medicamentos de internação (41,2\%); equipamentos $(28 \%)$ e serviços de enfermagem (17\%).

No Hospital os medicamentos de internação são lançados na conta do paciente na dispensação pela farmácia. No momento da préanálise das contas às enfermeiras auditoras, ao compará-las com os registros do prontuário clínico do paciente, observaram a presença de prescrições médicas incompletas, bem como a falta de checagem de medicamentos. Quando o medicamento não foi utilizado e retorna à farmácia é estornado, porém sabe-se que na prática clínica é possível que ocorra a utilização indevida de medicamentos de um paciente para outro com a mesma prescrição médica. 
Em relação ao maior impacto financeiro decorrente das exclusões os itens que mais contribuíram foram os materiais de Hemodinâmica, medicamentos utilizados na Hemodinâmica e gases.

Conforme mencionado anteriormente os materiais de Hemodinâmica, tais como cateter para valvoplastia pulmonar, fio guia, eletrodo temporário $5 \mathrm{~F}$, cateter angiográfico diagnóstico $6 \mathrm{~F}$, são de alto custo. Cita-se como exemplo, cateteres balão utilizados em angioplastia excluídos da conta de um único paciente, devido ao lançamento equivocado, gerando impacto de $\mathrm{R} \$ 94.373,00$.

As exclusões decorrentes dos medicamentos utilizados no Serviço de Hemodinâmica ocorreram por lançamentos incorretos no faturamento, tal como, a solicitação de uma enfermeira auditora da inclusão de $150 \mathrm{ml}$ de sevoflurano (agente anestésico líquido utilizado de forma inalatória), porém na UFA foram lançados na conta 150 frascos, justificando assim a exclusão de $R \$ 49.704,00$.

Durante a pré-análise das contas observa-se que não há uniformidade de registros, com destaque para anotações de enfermagem incompletas e preenchimento incorreto das notas de débito. Na rotina de documentação dos profissionais de enfermagem este preenchimento geralmente é feito ao final de cada plantão de forma pouco fidedigna, o que compromete a qualidade dos dados.

A deficiência e a falta de uniformidade dos registros não somente entre a equipe de enfermagem, mas também entre a equipe médica, ficaram evidentes com o excesso de ajustes positivos (inclusões) e negativos (exclusões) realizados pela equipe de auditoria da USS. Por meio da préanálise realizada pelas enfermeiras auditoras foram incluídos $R \$$ 1.877.168,64 e excluídos $R \$ 1.155 .351,36$ e da pré-análise feita pelos médicos auditores foram incluídos $R \$ 563.927,46$ e excluídos $R \$$ $657.190,19$.

O impacto destes ajustes no faturamento mostrou que a equipe de auditoria acrescentou $R \$ 628.554,55$ que seriam perdidos, se não fosse realizada a pré-análise. 
Das contas analisadas, $91,42 \%$ receberam ajustes positivos e negativos. A média de inclusões feitas pela equipe de auditoria foi de $R \$$ 1.340,75; e as exclusões foram em média de $\mathrm{R} \$ 1.571,58$.

Como descrito ao longo deste estudo há diferença entre os itens conferidos pelas enfermeiras e médicos auditores, tanto em relação à quantidade quanto em relação aos respectivos valores. Os itens de responsabilidade dos médicos possuíam maior valor financeiro, tendo sido mais excluídos. Porém constata-se que a quantidade de itens incluídos pelas enfermeiras proporcionou maior impacto financeiro ao faturamento hospitalar do período em questão.

As enfermeiras auditoras ajustaram nas contas muitos itens que seriam perdidos caso estas fossem apresentadas diretamente as fontes pagadoras, resultando em perdas financeiras significativas para a Instituição.

Consideraram-se no estudo os itens glosados das contas hospitalares após a auditoria. Porém, enquanto que na planilha das enfermeiras foram registradas as glosas, de maneira global, referentes à auditoria de enfermagem na planilha dos médicos não constavam as glosas relativas aos itens por eles auditados, ou seja, estavam documentados apenas os valores referentes à glosa total. Logo para efeito de cálculo das glosas dos itens auditados pelos médicos (em média de $\mathrm{R} \$ 311,94$ ) excluíram-se da glosa total os valores referentes à glosa de enfermagem.

$\mathrm{Na}$ ausência da documentação referente aos itens glosados auditados por médicos consultou-se um dos médicos auditores da USS que, a partir da sua experiência no processo de auditoria de contas hospitalares, destacou a falta de registros: de evoluções médicas no prontuário, especialmente de clínicos quando o paciente está em UTI e de médicos intensivistas não plantonistas; de evoluções médicas no prontuário de interconsultas; de descrição cirúrgica de procedimentos realizados à beira do leito ou em UTI, tais como, passagem de catéteres, cardioversões, drenagens; de anotações em ficha anestésica na Hemodinâmica; de evoluções dos médicos nutrólogos; de requisição e ou justificativa dos exames diagnósticos; de prescrição de isolamento. 
Os itens mais prevalentes nas glosas de enfermagem, média de $R \$ 255,84$, foram os materiais de internação, medicamentos de internação e materiais de Hemodinâmica, resultado semelhante ao obtido em estudo ${ }^{35}$ que revelou que $86 \%$ dos itens glosados corresponderam a materiais e $11,6 \%$ a medicamentos. Entretanto, apesar de constarem os itens glosados na planilha das enfermeiras auditoras não foi possível detalhar os materiais e medicamentos que mais impactaram por não estarem especificados.

Seria de fundamental importância que a equipe de auditoria da USS realizasse a documentação detalhada dos itens glosados pelas operadoras de planos de saúde a fim de propiciar o desenvolvimento de atividades educativas na Instituição visando o registro adequado das atividades realizadas, por toda equipe de saúde, no cuidado ao paciente e estabelecer estratégias conjuntas a fim de evitar comprometimento do faturamento.

Os itens auditados por enfermeiras que apresentaram maior impacto financeiro foram os equipamentos (média de $R \$ 392,75$ ); gases (média de $R \$ 292,33$ ) e medicamentos de internação (média de $R \$ 238,62$ ).

Em levantamento realizado no ano de 2011 pelas enfermeiras da USS, as glosas referentes aos equipamentos ocorreram devido à falta de registro do uso, principalmente de bombas de infusão. Oxigênio foi o gás que mais recebeu glosas por ausência de prescrição médica e de registros relativos à data e hora de inicio e término do tratamento, motivos também observados no estudo de Souza, Moura e Flores ${ }^{32}$.

$\mathrm{Na}$ prática de análise diária dos prontuários clínicos as enfermeiras auditoras têm observado que as glosas referentes aos medicamentos de internação devem-se à falta de checagem da prescrição médica, com destaque para os medicamentos de uso contínuo e dietas parenterais onde são checadas apenas a primeira instalação.

A experiência da autora na condição de enfermeira integrante da equipe de auditoria da Instituição possibilita-Ihe afirmar que não há o retorno à equipe de saúde em relação às falhas detectadas, por não existir ainda um trabalho conjunto entre a Diretoria Clínica, Divisão de Enfermagem e a USS. Portanto, os profissionais não têm conhecimento, sistematizado, de suas 
fragilidades de registro, das conseqüências delas advindas e não são efetivadas estratégias para melhorá-las e contribuir com o faturamento hospitalar.

Evidentemente não se pode eximir os profissionais de saúde da responsabilidade ética, legal, jurídica e comunicativa da documentação das ações prestadas ou das justificativas por elas não terem sido realizadas. Todavia, investimentos compartilhados para a realização de atividades educativas visando à melhoria dos registros contribuiriam sobremaneira para minimizar as divergências presentes ao se comparar o prontuário clínico e a conta do paciente.

Em relação aos registros de enfermagem, destaca-se que além de constituir importante fonte de informação para o processo de auditoria, têm como finalidade estabelecer a comunicação entre a equipe de enfermagem e a equipe multiprofissional envolvidas nos cuidados aos usuários e na continuidade da assistência; subsidiar a elaboração do plano assistencial; avaliar a qualidade dos serviços prestados; representar um documento legal para o usuário e para instituição; ser fonte de informação também para o ensino e a pesquisa ${ }^{53}$.

Para Carrijo, Oguisso ${ }^{54}$ as anotações de enfermagem constituemse em um importante meio de comunicação no contexto da equipe de saúde, sobretudo quando valorizadas e realizadas com um determinado padrão de qualidade, representando a assistência prestada tal como ocorreu, permitindo uma visão global do paciente. As autoras afirmam que a preocupação com a qualidade das anotações de enfermagem tem motivado pesquisadores a lutarem por registros mais substanciais em termo de conteúdo, forma, consistência, entendimento e legibilidade, entre outras características.

Enfatiza-se que além de investimentos conjuntos em programas de educação o conhecimento sobre os custos dos materiais, equipamentos e procedimentos realizados é imprescindível à equipe de enfermagem podendo contribuir para melhorar os registros da assistência prestada e diminuir as perdas de faturamento e glosas hospitalares ${ }^{37}$. 
Uma experiência exitosa em um hospital privado, onde a gerência de enfermagem e o Serviço de Educação Continuada criaram o cargo de enfermeira de faturamento hospitalar, demonstrou a melhora das anotações de enfermagem e diminuição das divergências entre as informações de prontuários e contas hospitalares. Com o treinamento da equipe de enfermagem do Centro Cirúrgico a respeito do faturamento constatou-se a diminuição do indicie de divergências de $38,2 \%$ para $15,8 \%{ }^{37}$.

Nesta perspectiva afirma-se que o conhecimento sobre os custos poderia ser disseminado entre toda a equipe de saúde para favorecer a obtenção de eficiência e eficácia dos recursos disponíveis, preservando padrões de qualidade assistencial e melhorando o processo de faturamento hospitalar.

Os dados referentes ao período estudado demonstram que a formação de contas parciais, a cada 10 dias, não tem minimizado o tempo de apresentação às fontes pagadoras (operadoras de planos de saúde), com média foi de 33,92 dias, conforme preconizado. Em decorrência de ter sido estabelecido que a UFA não enviaria à USS as contas que não possuíssem todos os documentos e autorizações necessárias para auditoria das operadoras de planos de saúde evidenciou-se que uma conta permanece, em média, 23,08 dias na UFA comprometendo o tempo de recebimento do InCor pelos serviços prestados.

Considerando-se o quadro de profissionais atuantes na USS e número de leitos destinados aos pacientes de operadoras de planos de saúde (110) propõe-se a discussão na Unidade da pertinência de realizar a auditoria concorrente das contas desses pacientes, do mesmo modo como são feitas com as contas dos pacientes particulares. Outra proposta para a redução do tempo de formação da conta seria que o lançamento das notas de débito fosse feito na própria unidade onde o paciente se encontra pelo auxiliar administrativo, ao invés desta ação ser realizada na USS.

Vislumbra-se que tais medidas facilitariam aos auditores a préanálise das contas hospitalares e favoreceria a realização de atividades educativas sistemáticas junto à equipe responsável pelos registros em 
prontuário, principal fonte de comprovação para o recebimento do pagamento dos serviços prestados.

A revisão contínua do processo de formação da conta hospitalar com o envolvimento da Diretoria Clínica, Divisão de Enfermagem, USS, UFA e equipe de saúde, possibilitará o enfrentamento dos desafios atuais e futuros auxiliando na minimização de divergências entre o prontuário e a conta hospitalar. 
Foram analisadas 2.613 contas hospitalares, referentes ao período de janeiro a dezembro de 2011, enviadas à USS para realização da préanálise pela equipe de auditoria.

Predominaram nas contas examinadas os pacientes do sexo masculino, com idade média de 64 anos e a especialidade Coronariana prevaleceu entre os diagnósticos médicos, conforme o esperado devido à especificidade assistencial do InCor HC-FMUSP.

O faturamento gerado por 34 operadoras de planos de saúde credenciadas na Instituição concentrou-se em 04 (62,9\%) delas, com a predominância da operadora A (27,6\%). Contudo o maior valor médio obtido por conta referiu-se a operadora $D$ com $R \$ 19.187,50$.

A internação dos pacientes em apartamento correspondeu, em média, a 4,26 (DP \pm 3,14) dias; em UTI a 4,48 (DP \pm 3,12) totalizando 5,41 dias de permanência na Instituição.

A realização do estudo permitiu as seguintes conclusões:

- Os itens componentes das contas hospitalares conferidas por enfermeiras que mais receberam ajustes positivos, no momento da pré-análise, foram gases $(90,5 \%)$; materiais de internação (85\%) e serviço de enfermagem $(83,2 \%)$;

- Os itens que tiveram maior impacto financeiro nos ajustes positivos foram os materiais de hemodinâmica com média de $R \$$

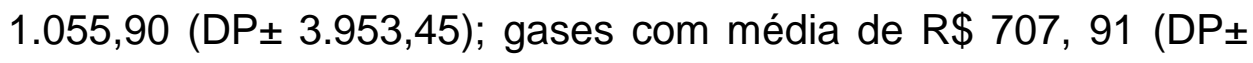
$843,95)$ e equipamentos com média de $R \$ 689,42$ (DP $\pm 1145,20$ );

- Os itens componentes das contas hospitalares mais excluídos foram os medicamentos de internação (41,2\%); equipamentos (28\%) e serviços de enfermagem (17\%);

- Em relação aos ajustes negativos os itens que tiveram maior impacto financeiro foram os materiais de Hemodinâmica com média de $\mathrm{R} \$ 3.860,15$ (DP \pm 15.220,80); medicamentos utilizados na Hemodinâmica com média de $\mathrm{R} \$ 1.983,04(\mathrm{DP} \pm 8.324,42) \mathrm{e}$ gases com média de $\mathrm{R} \$ 1.048,51(\mathrm{DP} \pm 3.025,53)$; 
- Durante a pré-análise das contas as enfermeiras incluíram $R \$$ 1.877.168,64 e excluíram $\mathrm{R} \$ 1.155 .351,36$ e os médicos incluíram $\mathrm{R} \$ 563.927,46$ e excluíram $\mathrm{R} \$ 657.190,19$;

- Caso não fosse realizada a pré-análise pela equipe de auditoria haveria a perda de $\mathrm{R} \$ 628.554,55$ no faturamento das contas hospitalares;

- Das 2.613 contas analisadas 91,42\% receberam ajustes, sendo $57,59 \%$ positivos, com média de $\mathrm{R} \$ 1.340,75$ (DP $\pm 2.502,93$ ) e $33,83 \%$ negativos, com média de $\mathrm{R} \$ 1.571,58$ ( $\mathrm{DP} \pm 5.990,51$ );

- O total de glosas dos itens analisados por enfermeiras ou por médicos, bem como em itens examinados por ambos, correspondeu em média a $\mathrm{R} \$ 380,51(\mathrm{DP} \pm 1.533,05) \mathrm{e}$

- As glosas referentes aos itens conferidos por médicos perfizeram um total médio de $\mathrm{R} \$ 311,94$ ( $\mathrm{DP} \pm 646,86$ ) e as glosas referentes aos itens conferidos por enfermeiras de $\mathrm{R} \$ 255,84$ (DP \pm $1.636,76)$.

Enfim considera-se que este estudo representa a possibilidade de avanço no conhecimento acerca da auditoria de contas hospitalares à medida que investigou o processo de pré-análise realizado por uma equipe de auditores constituída por enfermeiras e médicos. 


\section{REFERÊNCIAS}


1. Medici AC. Aspectos Teóricos e Conceituais do Financiamento das Políticas de Saúde. In: Piola SF e Vianna SM. Economia da Saúde: Conceitos e contribuições para a Gestão de Saúde. IPEA, Brasília: IPEA; 2002. Cap II. p 23-68.

2. Brasil. Ministério da Saúde. Conselho Nacional de Secretários da Saúde. Saúde Suplementar. Brasília: CONASS, 2007. [citado 13 Nov 2012] Disponível em :

http://bvsms.saude.gov.br/bvs/publicacoes/colec_progestores_livro11.pd $f$

3. IBGE. IBGE - Instituto Brasileiro de Geografia e Estatística. Consumo de bens e serviços de saúde chega a $8,8 \%$ do PIB. Rio de Janeiro: IBGE; 2009. [citado 13 Set 2012]. Disponível em: http://www.ibge.gov.br/home/presidencia/noticias/noticia visualiza.php?i $\mathrm{d}$ noticia $=2070$ \&id pagina $=1$ \&titulo=Consumo-de-bens-e-servicos-desaude-chega-a- $8,8 \%$-do-PIB

4. Organização Mundial da Saúde. [citado 18-ago-2012]. Disponível em: http://www.who.int/countries/bra/en/

5. Paim CRP, Ciconeli RM, Auditoria da avaliação da qualidade dos serviços de saúde. Revista de Administração em Saúde. 2007; 9(36): 85-91.

6. Whynes DK. Health care costs. Eur Heart J. 2002; 23: 1237-9.

7. Bittar E, Castilho V. O custo médio direto do material utilizado em cirurgia de revascularização do miocárdio. Rev Assoc Med Bras. 2003; 49: 255-60.

8. Haddad N, Bittar E, Marchi AF de, Kantorowitz CSV, Ayoub AC, Fonseca ML et al . Custos hospitalares da cirurgia de revascularização do miocárdio em pacientes coronarianos eletivos. Arq Bras Cardiol [periódico na Internet]. Abr 2007 [citado 23 fev 2012]; 88(4): 418-423. Disponível em:

http://www.scielo.br/scielo.php?script=sci_arttext\&pid=S0066782X2007000400009\&lng=en. http://dx.doi.org/10.1590/S0066$782 \times 2007000400009$

9. Castilho V, Castro LC, Couto AT, Maia FOM, Sasaki NY, Nomura FH et al . Levantamento das principais fontes de desperdício de unidades assistenciais de um hospital universitário. Rev. Esc. Enferm. USP 
[periódico na Internet]. 2011 Dez [citado 18 fev 2012]; 45(spe): 1613-20. Disponível em:

http://www.scielo.br/scielo.php?script=sci_arttext\&pid=S008062342011000700012\&lng=pt. http://dx.doi.org/10.1590/S008062342011000700012.

10. Francisco IMF, Castilho V. A enfermagem e o gerenciamento de custos. Rev Esc Enferm USP. 2002;36(3):240-4.

11. Martins D. Custos e Administração hospitalar. In: Custos e orçamentos hospitalares. São Paulo: Atlas, 2000. Cap 1 p. 17-21.

12. Paschoal MLH, Castilho V. Implementação do sistema de gestão de materiais informatizado do Hospital Universitário da Universidade de São Paulo. Rev Esc Enferm USP. [online]. 2010 Dez [citado $18 \mathrm{fev}$ 2012], 44(4):984-88 . Disponível em:

$<$ http://www.scielo.br/scielo.php?script=sci_arttext\&pid=S0080$62342010000400018 \&$ lng =pt\&nrm=iso $>$. ISSN 0080-6234. http://dx.doi.org/10.1590/S0080-62342010000400018.

13. Brunt, PD. Como reduzir custos: controlando gastos, eliminando desperdícios, trabalhando com eficiência. Tradução Sara Gedanke. São Paulo: Nobel, 1992.

14. Margarido ES, Castilho V. Aferição do tempo e do custo médio do trabalho da enfermeira na consulta de enfermagem. Rev Esc Enferm USP. 2006; 40(3):427-33.

15. Martins, E. Contabilidade de custos. 9aㅡ ed .São Paulo: Atlas; 2003. Terminologia contábil básica; p. 24-8.

16. Horngren CT, Foster G, Datar SM. Contabilidade de custos. $9^{\mathrm{a}}$ ed. Rio de Janeiro: LTC- Livros Técnicos e Científicos; 2000 701p.

17. Matos AJ. Gestão de custos hospitalares. São Paulo: Editora STS; 2002. 280p.

18. Mendes, KGL. A participação das enfermeiras na gestão de custos em organizações hospitalares [tese online]. São Paulo: Escola de Enfermagem; 2011 [citado 29 abr 2012]. Disponível em: http://www.teses.usp.br/teses/disponiveis/7/7140/tde-03102011$\underline{092928 / .}$ 
19. Castilho V, Fugulin FMT, Gaidzinski RR. Gerenciamento de custos nos serviços de enfermagem. In: Kurcgant P. Gerenciamento em enfermagem. 2a ed. Rio de Janeiro: Guanabara Koogan, 2005. Cap 13 p 169-80.

20. Lourenço KG, Castilho V. Classificação ABC dos materiais: uma ferramenta gerencial de custos em enfermagem. Rev Bras Enferm, (Brasília). 2006 jan- fev; 59 (1): 52-5.

21. Munhoz S, Ramos LH, Cunha ICKO. Custo padrão dos procedimentos de enfermagem na assistência de enfermagem na assistência ao paciente em terapia intensiva. Acta Paul Enferm (São Paulo). 2003; 16 (4); 77-85.

22. Nakao JRS. Estudo do pagamento da assistência de enfermagem hospitalar na rede privada do município de Ribeirão Preto [tese]. Ribeirão Preto (SP): Escola de Enfermagem de Ribeirão Preto, Universidade de São Paulo; 1995.

23. Abuderne P, Naisbitt J. Megatendência para mulheres. RJ: Rosa dos Tempos 1993.

24. Sandroni P. Dicionário de administração e finanças. São Paulo: Best Seller; 2001.

25. Zunta, RSB, Castilho V. O faturamento gerado pelos procedimentos de enfermagem em uma unidade de terapia intensiva. Rev Latino-Am Enfermagem. 2011;19(3) 573-80.

26. Buzatti CV, Chianca TC. Auditoria em enfermagem: erros e custos envolvidos nas anotações. Rev. Nursing (Barueri). 2005; 90(8); 46- 50.

27. D'Innocenzo M. Setz VG. Avaliação da qualidade dos registros de enfermagem no prontuário por meio da auditoria. Acta Paul. Enferm. 2009; 22 (3) p. 313-7

28. Camelo SHH, Pinheiro A, Campos D, Oliveira TL, Auditoria de enfermagem e qualidade da assistência a saúde: uma revisão de literatura. Rev. Eletr. Enf. 2009;11(4) 1018-25. 
29. Scarparo AF, Ferraz CA. Auditoria de enfermagem: identificando sua concepção e métodos. Rev Bras Enferm (Brasília). 2008 maio-jun; 61(3): 302-5.

30. Motta ALC. Auditoria de Enfermagem. In: Auditoria enfermagem nos hospitais e seguradoras de saúde 5a. ed. São Paulo: látria, 2010. Cap 01 p.17-9.

31. Pinto KA, Melo CMM de. A prática da enfermeira auditora em saúde. Rev Esc Enferm USP. 2010; 44(3):671-78.

32. Souza V, Moura FL, Flores ML. Fatores determinantes e conseqüências de falhas registradas na assistência de enfermagem: um processo educativo. Rev Min Enferm. 2002; 6 (1/2):30-4.

33. Scarparo AF, Ferraz CA, Chaves LDP, Rotta CSG. Abordagem conceitual de métodos e finalidade da auditoria de enfermagem. Rev Rene (Fortaleza). 2009 jan/mar; 10(1): 124-30.

34. Lobbadia LL, Adami NP. Avaliação das anotações de enfermagem em prontuários de um hospital universitário. Acta Paul Enferm. 2004; 17(1) p.55-62.

35. Rodrigues VA, Perroca MG, Jericó MC. Glosas hospitalares: importância das anotações de Enfermagem. Arq Ciênc Saúde. 2004 outdez;11(4):210-4.

36. Silva PC, Casa ECGS. Auditoria Interna em enfermagem e educação continuada: um feedback positivo. Rev Enferm UNISA. 2006; (7); 48-51.

37. Zunta RSB, Cardoso MLAP, Lisboa MAPLP, Castilho V. Treinamento com foco no faturamento assistencial: uma inovação no serviço de educação continuada. Mundo da Saúde (São Paulo). 2006; 30 (2); 2505 .

38. Francisco MTR. Auditoria em enfermagem: padrões, critérios de avaliação e instrumentos. 3a ed. São Paulo: Cedas: 1993.

39. Sousa P, Passos K, Torres L, Mulatinho L. Nursing audit: a contribution to minimizing the hospital glosses Rev enferm UFPE [on line]. [REUOL / DOI: 10.5205/01012007 / Qualis B 2] [periódico na Internet]. 2011 novembro 3; [Citado 2012 junho 21]; 5(10): 2479-2483. Disponível em: 
http://www.ufpe.br/revistaenfermagem/index.php/revista/article/view/204 0

40. Ferreira TS, Souza- Braga ALS. Auditoria de enfermagem: o impacto das anotações de enfermagem no contexto das glosas hospitalares. Aquichan. 2009; 9 (1):38-49

41. Galvão CR. Estudo do papel da auditoria de enfermagem para a redução dos desperdícios em materiais e medicamentos. O Mundo da saúde (São Paulo). 2002; 26 (2); 275 -82.

42. Yin RK. Estudo de caso: Planejamento e Método. Trad. de Ana Thorell. 4a ed. Porto Alegre: Bookman, 2010.

43. Jericó MC. Aplicação do Custeio Baseado em Atividades em Centro de Material. [tese-doutorado]. São Paulo (SP): Escola de Enfermagem da USP; 2008.

44. Filho UD. Introdução à Bioestatística para Simples Mortais. 7a ed. Negócio Editora, São Paulo, (1999).

45. World Health Organization. The World Health Report, 1998. Geneve: WHO, 1998.

46. IBGE. A condição dos idosos no domicílio. In: perfil dos idosos responsáveis pelos domicílios no Brasil. Rio de Janeiro: IBGE; 2002. $58 p$.

47. Favorato MECS, Favarato D, Hueb WA, Aldrighi JM. Qualidade de vida em portadores de doença arterial coronária: comparação entre gêneros. Rev Assoc Med Bras 2006; 52(4): 236-41.

48. Peixoto SV, Giatti L, Elmira A, Maria EA, Maria FLC. Cost of public hospitalization among ilderly in Brazil's Unified Health System. Epidemiol. Serv. Saúde. [online]. dic. 2004, vol.13, no.4 [citado 22 Out 2012] p.239-46. Disponível em: http://scielolab.iec.pa.gov.br/scielo.php?script=sci_arttext\&pid=S1679$9742004000400006 \&$ Ing=es\&nrm=iso $>$. ISSN 1679-4974.

49. Ribeiro RA, Mello RGB, Melchior R, Dill JC, Hohmann CB, Lucchese AM et al . Custo anual do manejo da cardiopatia isquêmica crônica no 
Brasil: perspectiva pública e privada. Arq Bras Cardiol. São Paulo. 2005; 85(1): 3-8. July 2005.

50. Albuquerque C, Piovesan MF, Santos IS, Martins ACM, Fonseca AL, Sasson D, et al . A situação atual do mercado da saúde suplementar no Brasil e apontamentos para o futuro. Ciênc. Saúde Coletiva [periódico na internet]. 2008. Out. [citado 23 Oct 2012];13(5): 1421-30. Disponível em: http://www.scielo.br/scielo.php?script=sci arttext\&pid=S1413$81232008000500008 \& \operatorname{lng}=$ en\&nrm=iso. $\mathrm{http}: / / \mathrm{dx}$. doi.org/10.1590/S141381232008000500008 .

51. Teixeira RVL. O retorno financeiro das atividades realizadas pela enfermagem em uma Unidade de terapia Intensiva. [dissertação]. São Paulo: Escola de Enfermagem da Universidade de São Paulo; 2012.

52. Cardoso CR. Contribuição do planejamento orçamentário no setor de hemodinâmica em um hospital universitário. [monografia] Porto Alegre: Universidade Federal de Porto Alegre; 2009.

53. Mira VL, Minami LF, Ferrari CRS, Ortiz DCF, Follador NN. Anotação de Enfermagem. In: Cianciarullo TI, Gualda DMR, Melleiro MM, Anabuki $\mathrm{MH}$. Sistema de Assistência de Enfermagem (SAE): evolução e tendências. 5a ed. São Paulo: Ícone; 2012. 259-72.

54. Carrijo AR, Oguisso T. Trajetória das Anotações de Enfermagem: um levantamento em periódicos nacionais (1957-2005). Rev Bras Enferm 2006; 59 (n.esp): 454-8. 
APÊNDICES 
APÊNDICE I - Instrumento de Coleta de Dados

\begin{tabular}{|c|c|c|c|c|c|c|c|c|c|c|c|c|c|c|c|c|c|}
\hline \multirow[b]{2}{*}{ REGISTRO } & \multirow[b]{2}{*}{ CONVENIO } & \multirow[b]{2}{*}{ SEXO } & \multirow[b]{2}{*}{ IDADE } & \multirow[b]{2}{*}{ PCTE } & \multirow[b]{2}{*}{ О́вІто } & \multirow[b]{2}{*}{ DIAG } & \multirow[b]{2}{*}{ GRUPO } & \multicolumn{3}{|c|}{ DIÁRIAS } & \multicolumn{2}{|c|}{ DATA } & \multicolumn{5}{|c|}{ VALOR } \\
\hline & & & & & & & & APTO & UTI & PERM & INICIO & FINAL & INICIO & $\begin{array}{c}\text { PRÉ- } \\
\text { ANÁLISE }\end{array}$ & AJUSTE & FINAL & GLOSA \\
\hline & & & & & & & & & & & & & & & & & \\
\hline & & & & & & & & & & & & & & & & & \\
\hline & & & & & & & & & & & & & & & & & \\
\hline & & & & & & & & & & & & & & & & & \\
\hline & & & & & & & & & & & & & & & & & \\
\hline & & & & & & & & & & & & & & & & & \\
\hline & & & & & & & & & & & & & & & & & \\
\hline & & & & & & & & & & & & & & & & & \\
\hline & & & & & & & & & & & & & & & & & \\
\hline & & & & & & & & & & & & & & & & & \\
\hline & & & & & & & & & & & & & & & & & \\
\hline & & & & & & & & & & & & & & & & & \\
\hline & & & & & & & & & & & & & & & & & \\
\hline & & & & & & & & & & & & & & & & & \\
\hline & & & & & & & & & & & & & & & & & \\
\hline & & & & & & & & & & & & & & & & & \\
\hline & & & & & & & & & & & & & & & & & \\
\hline & & & & & & & & & & & & & & & & & \\
\hline & & & & & & & & & & & & & & & & & \\
\hline & & & & & & & & & & & & & & & & & \\
\hline & & & & & & & & & & & & & & & & & \\
\hline
\end{tabular}




\section{APÊNDICE I - Instrumento de Coleta de Dados (continuação)}

\begin{tabular}{|c|c|c|c|c|c|c|c|c|c|c|c|c|c|c|c|c|c|c|c|c|c|}
\hline \multicolumn{4}{|c|}{ SERVIÇO DE ENFERMAGEM } & \multicolumn{5}{|c|}{ EQUIPAMENTOS } & \multicolumn{4}{|c|}{ GASES } & \multicolumn{5}{|c|}{ MATERIAIS INTERNAÇÃO } & \multicolumn{4}{|c|}{ MEDICAMENTO INTERNAÇÃO } \\
\hline PRÉ & Pós & AJUSTE & GLOSA & PRÉ & Pós & AJUSTE & DIV & GLOSA & PRÉ & Pós & AJUSTE & GLOSA & PRÉ & Pós & AJUSTE & DIV & GLOSA & PRÉ & Pós & AJUSTE & GLOSA \\
\hline & & & & & & & & & & & & & & & & & & & & & \\
\hline & & & & & & & & & & & & & & & & & & & & & \\
\hline & & & & & & & & & & & & & & & & & & & & & \\
\hline & & & & & & & & & & & & & & & & & & & & & \\
\hline & & & & & & & & & & & & & & & & & & & & & \\
\hline & & & & & & & & & & & & & & & & & & & & & \\
\hline & & & & & & & & & & & & & & & & & & & & & \\
\hline & & & & & & & & & & & & & & & & & & & & & \\
\hline & & & & & & & & & & & & & & & & & & & & & \\
\hline & & & & & & & & & & & & & & & & & & & & & \\
\hline & & & & & & & & & & & & & & & & & & & & & \\
\hline & & & & & & & & & & & & & & & & & & & & & \\
\hline & & & & & & & & & & & & & & & & & & & & & \\
\hline & & & & & & & & & & & & & & & & & & & & & \\
\hline & & & & & & & & & & & & & & & & & & & & & \\
\hline & & & & & & & & & & & & & & & & & & & & & \\
\hline & & & & & & & & & & & & & & & & & & & & & \\
\hline
\end{tabular}




\section{APÊNDICE I - Instrumento de Coleta de Dados (continuação)}

\begin{tabular}{|c|c|c|c|c|c|c|c|c|c|c|c|c|c|c|c|c|c|c|c|c|c|}
\hline \multicolumn{5}{|c|}{ MATERIAL CENTRO CIRURGICO } & \multicolumn{4}{|c|}{$\begin{array}{l}\text { MEDICAMENTO CENTRO } \\
\text { CIRURGICO }\end{array}$} & \multicolumn{5}{|c|}{ MATERIAL HEMODINÂMICA } & \multicolumn{4}{|c|}{$\begin{array}{l}\text { MEDICAMENTO } \\
\text { HEMODINÂMICA }\end{array}$} & \multicolumn{4}{|c|}{ TEMPO CONTA } \\
\hline PRÉ & Pós & AJUSTE & DIV & GLOSA & PRÉ & Pós & AJUSTE & GLOSA & PRÉ & Pós & AJUSTE & DIV & GLOSA & PRÉ & Pós & AJUSTE & GLOSA & UFA & USS & AUD & FIM \\
\hline & & & & & & & & & & & & & & & & & & & & & \\
\hline & & & & & & & & & & & & & & & & & & & & & \\
\hline & & & & & & & & & & & & & & & & & & & & & \\
\hline & & & & & & & & & & & & & & & & & & & & & \\
\hline & & & & & & & & & & & & & & & & & & & & & \\
\hline & & & & & & & & & & & & & & & & & & & & & \\
\hline & & & & & & & & & & & & & & & & & & & & & \\
\hline & & & & & & & & & & & & & & & & & & & & & \\
\hline & & & & & & & & & & & & & & & & & & & & & \\
\hline & & & & & & & & & & & & & & & & & & & & & \\
\hline & & & & & & & & & & & & & & & & & & & & & \\
\hline & & & & & & & & & & & & & & & & & & & & & \\
\hline & & & & & & & & & & & & & & & & & & & & & \\
\hline & & & & & & & & & & & & & & & & & & & & & \\
\hline & & & & & & & & & & & & & & & & & & & & & \\
\hline & & & & & & & & & & & & & & & & & & & & & \\
\hline & & & & & & & & & & & & & & & & & & & & & \\
\hline
\end{tabular}




\section{APÊNDICE II - Agrupamento dos Diagnósticos médicos em}

\section{especialidades}

\begin{tabular}{|c|c|}
\hline ARRITMIA & $\begin{array}{l}\text { Ablação + Infarto Agudo do Miocárdio } \\
\text { Arritmia } \\
\text { Bloqueio Atrioventricular Total } \\
\text { Cardio Desfibrilador Implantável } \\
\text { Estudo Eletro Fisiológico } \\
\text { Fibrilação atrial } \\
\text { Implante de Marcapasso } \\
\text { Recolocação de eletrodo } \\
\text { Retirada Cardio Desfibrilador } \\
\text { Retirada Marca Passo } \\
\text { Síncope } \\
\text { Taquicardia Paroxística Supra Ventricular } \\
\text { Taquicardia Ventricular } \\
\text { Taquicardia Ventricular + Tamponamento } \\
\text { Troca de gerador } \\
\text { Troca eletrodo }\end{array}$ \\
\hline $\begin{array}{l}\text { CARDIOLOGIA } \\
\text { GERAL }\end{array}$ & $\begin{array}{l}\text { Anemia } \\
\text { Choque cardiogênico + abdome agudo perfurativo } \\
\text { Choque séptico } \\
\text { Dengue + Insuficiência Cardíaca Congestiva } \\
\text { Distúrbio de coagulação } \\
\text { Herpes zoster } \\
\text { Hipertensão Arterial Sistêmica } \\
\text { Hipertensão pulmonar } \\
\text { Infecção sítio cirúrgico } \\
\text { Insuficiência Cardíaca Congestiva } \\
\text { Osteomielite } \\
\text { Pericardiectomia } \\
\text { Pericardite } \\
\text { Púrpura } \\
\text { Sepse } \\
\end{array}$ \\
\hline $\begin{array}{l}\text { CARDIOPATIAS } \\
\text { CONGÊNITAS }\end{array}$ & $\begin{array}{l}\text { Atresia pulmonar } \\
\text { Coarctação de Aorta } \\
\text { Comunicação Inter Atrial } \\
\text { Comunicação Inter Atrial +Persistência do Canal Arterial } \\
\text { Comunicação Inter Ventricular } \\
\text { Comunicação Inter Ventricular +Comunicação Inter Atrial } \\
\text { Defeito do Septo Átrio- Ventricular } \\
\text { Defeito do Septo Átrio- Ventricular Total } \\
\text { Drenagem anômala Veias Pulmonares } \\
\text { Oclusão percutânea de Canal Arterial } \\
\text { Oclusão percutânea de Comunicação Inter Atrial } \\
\text { Oclusão percutânea de Comunicação Inter Atrial + } \\
\text { Embolectomia } \\
\text { Pectus escavatum } \\
\text { Persistência do Canal Arterial } \\
\text { Persistência do Canal Arterial + Comunicação Inter Atrial } \\
\text { Retirada shunt permanente } \\
\text { Tetralogia de Fallot } \\
\text { Transposição Grandes Artérias } \\
\text { Ventrículo único }\end{array}$ \\
\hline
\end{tabular}




\begin{tabular}{|c|c|}
\hline CIRURGIA GERAL & $\begin{array}{l}\text { Abdômen agudo } \\
\text { Apendicite } \\
\text { Colecistectomia } \\
\text { Colectomia } \\
\text { Coledocolitíase } \\
\text { Colonoscopia } \\
\text { Derrame pericárdico } \\
\text { Diverticulite } \\
\text { Drenagem de Pericárdio } \\
\text { Embolização de hemoptises } \\
\text { Esofagectomia } \\
\text { Granuloma corpo estranho } \\
\text { Hemorragia digestiva } \\
\text { Hepatectomia parcial } \\
\text { Hérnia inguinal } \\
\text { Lipoma } \\
\text { Mediastinoscopia e biópsia } \\
\text { Mesotelioma } \\
\text { Mixoma Átrio Esquerdo } \\
\text { Neo de Cólon } \\
\text { Nódulo } \\
\text { Obstrução vias biliares } \\
\text { Polipectomia Cólon } \\
\text { Ressecção endoscópica próstata } \\
\text { Retirada fio aço } \\
\text { Retirada granuloma } \\
\text { Simpatectomia } \\
\text { Tumor Átrio Esquerdo } \\
\text { Tumor de Cólon } \\
\text { Tumor de mediastino } \\
\text { Tumor de pâncreas } \\
\text { Tumor glúteo } \\
\text { Volvo + hérnia } \\
\end{array}$ \\
\hline CORONARIOPATIAS & $\begin{array}{l}\text { Doença Arterial Coronariana } \\
\text { Doença Arterial Coronariana + Angioplastia } \\
\text { Doença Arterial Coronariana+Cateterismo } \\
\text { Infarto Agudo do Miocárdio + Angioplastia } \\
\text { Infarto Agudo do Miocárdio+ Cateterismo } \\
\text { Infarto Agudo do Miocárdio }\end{array}$ \\
\hline NEFROLOGIA & $\begin{array}{l}\text { Insuficiência Renal } \\
\text { Nefrite }\end{array}$ \\
\hline PNEUMOLOGIA & $\begin{array}{l}\text { Biópsia de pulmão } \\
\text { Biópsia de traquéia } \\
\text { Biópsia trans brônquica } \\
\text { Broncoscopia } \\
\text { Bronquectasia } \\
\text { Bronquite } \\
\text { Decorticação pleural } \\
\text { Derrame pleural } \\
\text { Dispneia } \\
\text { Doença Pulmonar Obstrutiva Crônica } \\
\text { Estenose de traquéia } \\
\text { Lipoma torácico }\end{array}$ \\
\hline
\end{tabular}




\begin{tabular}{|c|c|}
\hline PNEUMOLOGIA & $\begin{array}{l}\text { Lobectomia } \\
\text { Lobectomia radical } \\
\text { Pneumonia } \\
\text { Prótese traqueal } \\
\text { Traqueoplastia } \\
\text { Traqueostomia } \\
\text { Tumor de pulmão } \\
\text { Tumor de tireoide } \\
\text { Tumor de traquéia }\end{array}$ \\
\hline TRANSPLANTE & $\begin{array}{l}\text { Biópsia miocárdio } \\
\text { Infecção em transplantado } \\
\text { Rejeição de Transplante } \\
\text { Transplante cardíaco } \\
\end{array}$ \\
\hline VALVOPATIAS & $\begin{array}{l}\text { Dupla lesão aórtica } \\
\text { Dupla troca valvar } \\
\text { Endocardite } \\
\text { Estenose aórtica } \\
\text { Estenose mitral + cateterismo } \\
\text { Estenose tricúspide } \\
\text { Insuficiência Mitral } \\
\text { Plastia aórtica } \\
\text { Plastia mitral } \\
\text { Plastia mitral + ablação } \\
\text { Troca mitral } \\
\text { Troca percutânea Válvula Aórtica } \\
\text { Troca valva aórtica } \\
\text { Troca valvar percutânea } \\
\text { Troca válvula pulmonar } \\
\text { Trombose de prótese Aórtica } \\
\text { Valvoplastia } \\
\text { Valvoplastia mitral } \\
\text { Valvoplastia pulmonar } \\
\end{array}$ \\
\hline VASCULAR & $\begin{array}{l}\text { Aneurisma Aorta Abdominal } \\
\text { Aneurisma Artéria Femoral } \\
\text { Aneurisma de Aorta } \\
\text { Aortoplastia } \\
\text { Acidente Vascular Cerebral } \\
\text { Amputação 3o Pododáctilo Direito } \\
\text { Amputação membro inferior esquerdo } \\
\text { Celulite } \\
\text { Celulite membro inferior direito } \\
\text { Confecção fístula Artério- venosa } \\
\text { Desbridamento pé } \\
\text { Embolectomia pulmonar } \\
\text { Endarterectomia de carótidas } \\
\text { Erisipela } \\
\text { Estenose carótidas } \\
\text { Estenose subclávia } \\
\text { Flebite em Membros Inferiores } \\
\text { Implante Porto-cath } \\
\text { Pé diabético } \\
\text { Pseudo-aneurisma femoral }\end{array}$ \\
\hline
\end{tabular}




\begin{tabular}{|l|l|}
\hline \multirow{4}{*}{ VASCULAR } & Pseudo-aneurisma membro inferior direito \\
& Trombo Embolismo Pulmonar \\
& Trombo embolectomia membros superiores \\
& Trombo endarterectomia membros inferiores \\
& Trombose venosa profunda \\
& Úlcera pé + Insuficiência Cardíaca Congestiva \\
& Varizes em membros inferiores \\
\hline
\end{tabular}




\section{ANEXO I - Autorização junto a Diretoria da USS}

IImo. sennor

Enio Jorge Salu

Diretor Comercial e de Saúde Suplementar (SS)

Instituto do Coração do Hospital das Clínicas da Faculdade de Medicina da Universidade de São Paulo (InCor do HCFMUSP)

Meu nome é Gabriela Favaro Faria Guerrer, mestranda do Programa de PósGraduação em Gerenciamento em Enfermagem da Escola de Enfermagem da Universidade de São Paulo (EEUSP). Pretendo desenvolver a pesquisa "Avaliação da Auditoria de Contas em Hospital de Ensino Especializado em Cardiologia e Pneumologia", sob a orientação do Prof. Dr Antônio Fernandes Costa Lima.

Esta pesquisa tem como objetivos: Verificar os itens componentes das contas dos pacientes internados, em um hospital de nível terciário especializado em cardiologia e pneumologia, que mais recebem ajustes no momento da pré-análise; Calcular o faturamento que os auditores conseguem acrescentar nas contas dos pacientes internados por meio da préanálise; Identificar o faturamento gerado pelos itens componentes das contas dos pacientes e Identificar as glosas nas contas dos pacientes relacionadas aos itens conferidos pelas enfermeiras auditoras.

Para tanto, solicitamos a valiosa e inestimável colaboração de VSa favorecendo o acesso aos dados coletados pelos auditores da USS no período de janeiro a dezembro de 2011.

Consideramos que os resultados obtidos poderão subsidiar a USS na condução de estratégias visando a melhoria da composição da conta hospitalar, bem como a diminuição de perdas no faturamento.

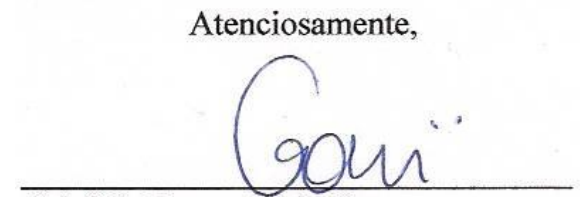

Gabriela Favaro Faria Guerrer Av Dr Eneas de Carvalho Aguiar, 44 Cerquera César - São Paulo / SP CEP:05403-000

Fone: 2661-5000 Ramal: 5969

E-mail: gabriela.faria@incor.usp.br

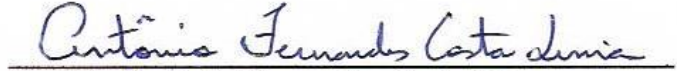

Prof Dr Antônio Fernandes Costa Lima Avenida Dr Enéas de Carvalho Aguiar, 419 Cerqueira César - São Paulo / SP CEP: 05403-000

Fone: 3061-7551

E-mail: tonifer@usp.br

De acordo,

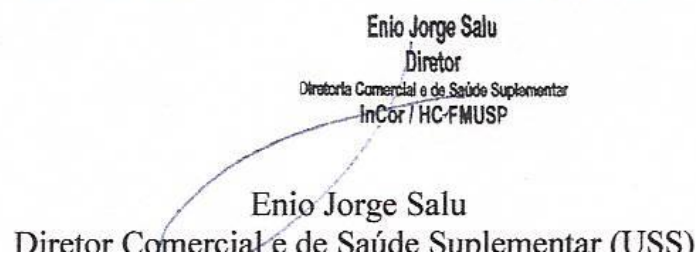




\title{
ANEXO II - Aprovação pelo Comitê de Ética em Pesquisa da Escola de Enfermagem da Universidade de São Paulo
}

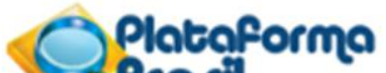

\author{
ESCOLA DE ENFERMAGEM DA \\ UNIVERSIDADE DE SÃO \\ PAULO - EEUSP
}

PROJETO DE PESQUISA

Pesquisador: Antonio Fernandes Costa Lima

Título: Avaliação da Auditoria de Contas em um Hospital de Ensino Especializado em Cardiologia e Pneumologia

Instituição: Escola de Enfermagem da Universidade de São Paulo - EEUSP

Versão: 1

CAAE: 01737712.0 .0000 .5392

\section{PARECER CONSUBSTANCIADO DO CEP}

Número do Parecer: 12980

Data da Relatoria: 17/04/2012

\section{Apresentação do Projeto:}

Trata-se de pesquisa exploratória, descritiva, retrospectiva, de abordagem quantitativa na modalidade de estudo de caso, que se propõe a analisar as contas dos pacientes internados, por convênios e particulares, no Instituto do Coração (InCor) do Hospital das Clínicas da Faculdade de Medicina da Universidade de São Paulo (HCFMUSP), durante o período de janeiro a dezembro de 2011. Esses dados serão coletados no banco de dados dos auditores que registram, diariamente, as contas e os valores em planilhas eletrônicas. A partir daí,serão agrupados e transportados para planilhas eletrônicas do Microsof Excel®. As variáveis categóricas de interesse serão analisadas pelo número absoluto e relativo das respostas, demonstrados em tabelas e gráficos.

\section{Objetivo da Pesquisa:}

- Verificar os itens componentes das contas dos pacientes internados, em um hospital de nível terciário especializado em cardiologia e pneumologia, que mais recebem ajustes no momento da pré-análise;

- Calcular o faturamento que os auditores conseguem acrescentar nas contas dos pacientes internados por meio da pré-análise;

- Identificar o faturamento gerado pelos itens componentes das contas dos pacientes;

- Identificar as glosas nas contas dos pacientes relacionadas aos itens conferidos pelas enfermeiras auditoras. 


\section{Avaliação dos Riscos e Benefícios:}

Segundo a pesquisadora, o estudo não apresenta riscos de quaisquer natureza. Por outro lado, o mesmo poderá contribuir, de modo geral, com o aumento do conhecimento das contas hospitalares; e, especificamente para a Instituição Coparticipante, poderá conduzir a Unidade de Saúde Suplementar para a melhoria da composição de suas contas, bem como para a diminuição de perdas no faturamento.

\section{Comentários e Considerações sobre a Pesquisa:}

Trata-se de um projeto de pesquisa bem escrito, bem fundamentado e bem delineado, que alinha-se à Res. 196/96.

\section{Considerações sobre os Termos de apresentação obrigatória:}

- Dispensa do TCLE: Como se trata de uma pesquisa de gerenciamento de custos, ou seja, de natureza administrativa e contabilística, conclui-se pela dispensa do TCLE.

- Autorização da Instituição Coparticipante: Foi juntada a anuência do Diretor Comercial e de Saúde Suplementar (USS) do InCor do HCFMUSP.

- Cronograma: viável.

- Orçamento: os recursos financeiros orçados serão arcados pela pesquisadora.

\section{Recomendações:}

Nada a acrescentar.

\section{Conclusões ou Pendências e Lista de Inadequações:}

Opina-se pela aprovação do projeto de pesquisa pelo CEP.

Necessita Apreciação da CONEP: Não

Situação do Parecer: Aprovado

Considerações Finais a critério do CEP:

17 de Abril de 2012

Assinado por: Célia Maria Sivalli Campos 